\title{
An Experimental Investigation of the Confluent Boundary Layer on a High-Lift System
}

$$
\text { by }
$$

F. O. Thomas and R. C. Nelson

\section{Prepared for NASA Ames Research Center under Grant NAG2-905}

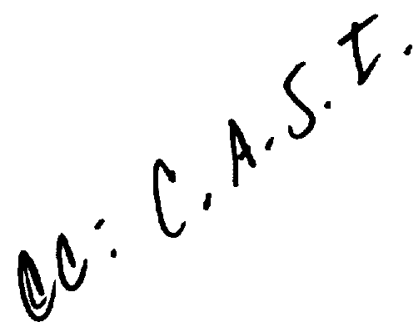




\begin{abstract}
This paper describes a fundamental experimental investigation of the confluent boundary layer generated by the interaction of a leading-edge slat wake with the boundary layer on the main element of a multi-element airfoil model. The slat and airfoil model geometry are both fully two-dimensional. The research reported in this paper is performed in an attempt to investigate the flow physics of confluent boundary layers and to build an archival data base on the interaction of the slat wake and the main element wall layer. In addition, an attempt is made to clearly identify the role that slat wake / airfoil boundary layer confluence has on lift production and how this occurs. Although complete LDV flow surveys were performed for a variety of slat gap and overhang settings, in this report the focus is on two cases representing both strong and weak wake boundary layer confluence.
\end{abstract}




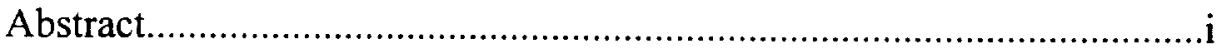

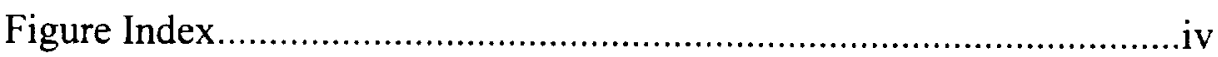

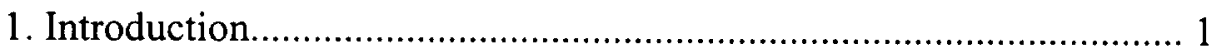

1.1 Background................................................................ 1

1.2 Research Objective......................................................... 5

1.3 Previous Confluent Boundary Layer Studies...........................5

2. Experimental Facility and Measurement Apparatus...........................

3. Experimental Results..................................................................12

3.1 Summary of Flow Visualization and Integrated Lift Results......12

3.2 Confluent Boundary Layer LDV Flow Field Surveys................16

3.2.1 Mean Flow Development for Cases 1 and 2...............16

3.2.2 Turbulence Quantities for Cases 1 and 2.................28

3.3 Unsteady Aspects of the High-Lift Flow Field.........................34

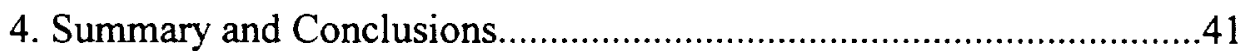




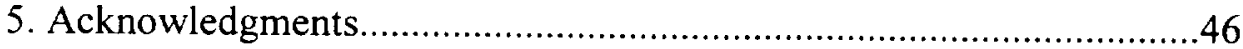

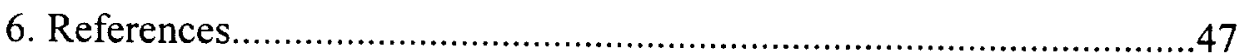




\section{List of Figures}

1. Schematic of Loading Created by a Slat and Flap ................................2

2. Schematic of the Multi-Element Airfoil Model.......................................8

3. Lift Coefficient Contours in Slat Gap - Overhang Parameter Space.....13

4. Summary Sketches of Flow Visualization Results................................14

5. Comparison of Case 1 and Case 2 Mean Velocity Profiles....................18

6a. Inner Variable Scaling of Mean Velocity: Case 2, $\mathrm{x} / \mathrm{c}=0.6 \ldots \ldots \ldots \ldots \ldots . .19$

6b. Inner Variable Scaling of Mean Velocity: Case1, $\mathrm{x} / \mathrm{c}=0.6 \ldots \ldots \ldots \ldots \ldots . . .19$

7. Velocity Defect Scaling of Case 2 Mean Velocity Profiles......................21

8. Streamwise Variation in Non-Dimensional Velocity Defect at Selected Wall Normal Locations for Case 2 ..........................................22

9. Comparison of Conventional and Confluent Boundary Layer Profiles.

10. Velocity Defect Scaling of Case 1 Mean Velocity Profiles. .24

11. Chordwise Variation in Displacement Thickness...................................25

12a. Local Normal Component Mean Velocity Profiles at $\mathrm{x} / \mathrm{c}=0.2 \ldots \ldots \ldots \ldots .26$

12b. Local Normal Component Mean Velocity Profiles at $\mathrm{x} / \mathrm{c}=0.6 \ldots \ldots \ldots \ldots .27$

12c. Schematic Showing Origin of Mean V Profiles Shape ...........................27

13. Tangential and Normal Component Turbulence Intensities for Case $2 . . .29$

14. Tangential and Normal Component Turbulence Intensities for Case $1 . . .30$

15. Non-Dimensional $\overline{u^{\prime} v^{\prime}}$ Profiles for Case 2 .............................................

16. Regions of Counter-Gradient Momentum Transport.................................33

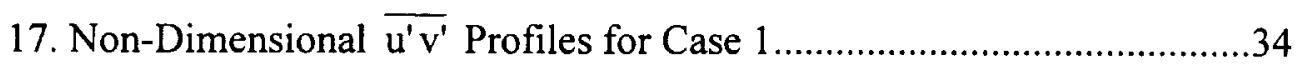


18. V-Component Velocity Histograms for Case 1

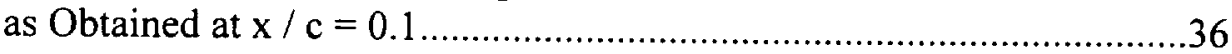

19. Hot-Wire Measurements Obtained Immediately Downstream

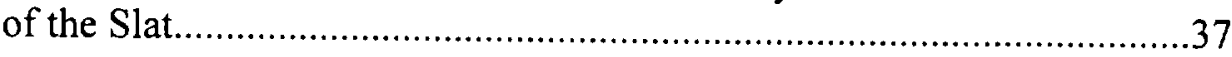

20. Autospectral Density Measurements of Wake Velocity Fluctuations......38

21. Wavelet Map of the Case 1 Slat Wake Velocity Fluctuations. 


\section{INTRODUCTION}

\subsection{Background}

A. M. O. Smith ${ }^{1}$ presented a thorough discussion of multi-element airfoil performance in his Wright Brothers Lecture. Conceptually the performance of a multielement airfoil can be explained using a simple inviscid model. Figure 1 presents a simple sketch illustrating the effect of a trailing flap and a leading-edge slat. The trailing flap can be thought of as a circulation device (i.e. a bound vortex) that creates an upwash over the main airfoil element. If the main element is replaced by a continuous vorticity distribution, as is done in thin airfoil theory, then a unique circulation distribution can be determined by satisfying the boundary condition that there is no flow normal to the airfoil surface (the flow tangency condition) and that the flow leaves tangent to the trailing-edge of the main element (the Kutta condition). The upwash created by the trailing flap effectively increases the vorticity loading over the main wing, particularly toward the trailing-edge. This causes an increase in the suction pressure distribution and consequently the lift force generated by the main element. The higher pressure loading is illustrated qualitatively in Figure 1. A similar argument can be made for a multisegmented flap system. Additional flaps can be used to improve the high-lift performance at the expense of increased system complexity. Of course, the real high-lift performance of an airfoil/flap configuration is limited by the occurrence of flow separation over either the main element or flap.

The performance of a wing/trailing flap system can be improved by the addition of a leading-edge device such as a slat. The influence of the slat on the high-lift system performance can also be explained by considering the slat as a circulation device. As 
shown in Figure 1, a loaded slat creates a downwash flow field over the main element that counters the main element flow over the nose. Again from thin airfoil theory one can show that the downwash from the slat will cause a reduction in the magnitude of the suction pressure peak over the wing leading-edge. The lowering of the pressure peak over the main element reduces the severity of the adverse pressure gradient and lessens the chance of flow separation. By delaying flow separation over the main element the multi-element airfoil section can be placed at a higher angle of attack than would be possible without the slat, thus improving the lift capability of the system.

Two element airfoil with flap deployed
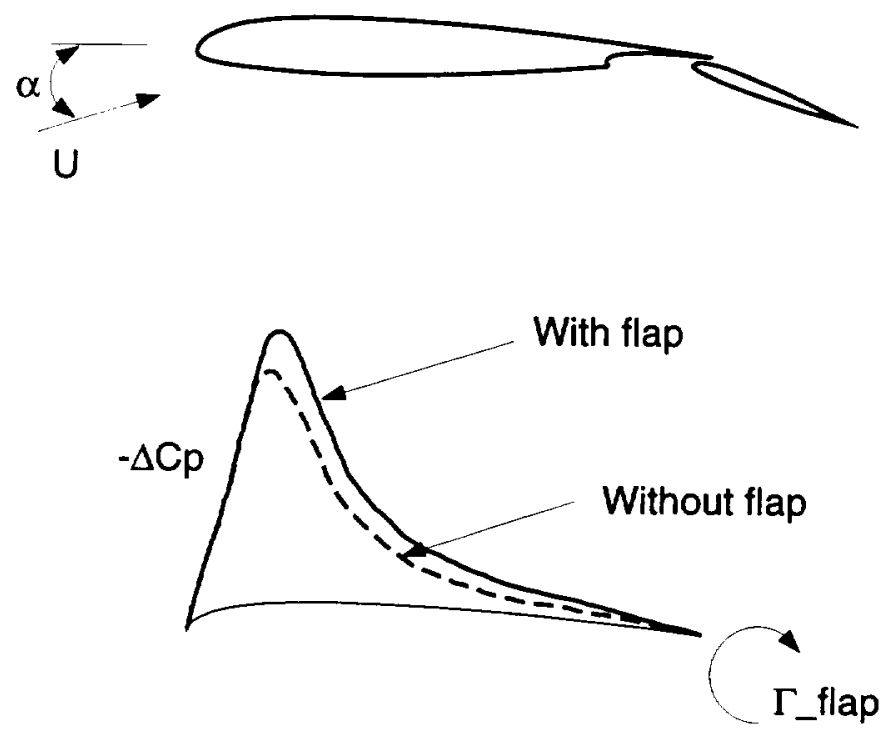

Two element airfoil with slat deployed

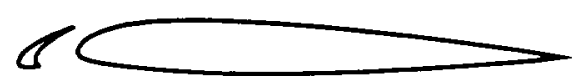

Figure 1. Schematic of Loading Created by a Slat and Flap 
Although simple inviscid arguments like those outlined above can be used qualitatively to explain how a multi-element airfoil generates high-lift, it is well known that the actual performance of the multi-element airfoil is governed by numerous viscous effects such as flow separation and the interaction of the wake of one element with the boundary layer of a downstream element.

As an example of the influence of viscous effects on the high-lift performance of multi-element airfoils, let us consider the interaction of the wake generated by the slat with the boundary layer over the main airfoil element. The geometric spacing of the slat relative to the main wing element is one obvious controlling factor on the extent of the slat wake/main element boundary layer interaction. As the gap between the slat and wing is made smaller the slat wake will begin to merge with the wing boundary layer. This mixing of the wake and boundary layer is commonly referred to as a "confluent boundary layer". The location of onset of confluence moves forward on the wing as the gap is decreased. The resulting confluent boundary layer will be thicker than the main element boundary layer alone, which increases the likelihood of flow separation on the main element and leads to a deterioration in high-lift performance. By increasing the gap spacing one can avoid slat wake and wing boundary layer interaction. However if the gap is too large the moderation effect that the slat has on the wing leading-edge suction peak can be lost. The large suction peak and the corresponding adverse pressure gradient will cause the flow to separate from the wing and result in a lowering of the maximum lift produced by the multi-element system.

From this very brief discussion of one possible viscous effect on a high-lift system it is apparent that prediction of the performance of a multi-element airfoil using CFD will 
require accurate modeling of the relevant viscous interactions. The development of a useful CFD-based design tool for high-lift system aerodynamic performance prediction requires increased attention to fundamental flow field physics issues. This may not be as daunting a task as it first seems. The computation of flow over multi-element high-lift systems requires an ability to successfully model certain high-lift system "building block flows" which are essential generic components of the flow field over any modern high-lift system. These characteristic building block flows are listed in Table 1.

\section{Table 1. High-Lift System Building Block Flows}

- Leading-edge transition mechanism;

- Separated flow phenomena (e.g. laminar bubbles and large scale cove flow separation);

- Confluent boundary layer flow;

- Boundary layer and wake development in arbitrary pressure gradients and with streamline curvature;

- Relaminarization;

- Multiple wake interactions.

The authors feel that the approach that needs to be taken to improve CFD capability for high-lift performance prediction is to develop a series of numerical and physical experiments to address fundamental flow physics issues surrounding each of the building block flows cited in Table 1. Preferably these studies would be jointly designed by computational and experimental researchers. Studying the individual building block flows 
through a combination of fundamental numerical and physical experiments is probably the most expeditious and cost effective way of developing reliable CFD design tools for high-lift systems. To attempt to compute the complicated viscous flow interactions associated with lift production on three-dimensional multi-element wings without a better understanding of the flow physics will, at best, produce solutions of dubious quality and may, in fact, ultimately impede the acceptance of CFD tools by the design community.

\subsection{Research Objective}

The research described in this report was supported by NASA Ames Research Center, Moffett Field, CA., under grant NASA-NAG2-905. The work was performed in an attempt to: (1) investigate the basic flow field physics of confluent boundary layers in a geometry and pressure gradient environment similar to that which occurs in actual highlift systems and (2) to build an archival experimental data base on the interaction of the slat wake and main element wall layer that would be useful for comparison with CFD simulations.

\subsection{Previous Confluent Boundary Layer Studies}

Despite the important role played by confluent boundary layers in high-lift system performance, our understanding of the physics associated with this flow is actually quite limited. Experimental work on confluent boundary layers generally falls into two broad categories. There have been studies on specific 2-D high-lift configuration models in both low speed and pressure tunnels. These studies have typically been carried out as part of a high-lift system configuration optimization and performance testing program ${ }^{2,3}$. As such, the focus is often not on the confluent layer itself but rather the resulting integrated aerodynamic forces. Measurements of the confluent boundary layer typically involve total 
head tube surveys which provide one component time mean velocity profiles. In addition, such studies include effects attributable not only to the confluence itself but also pressure gradient and streamwise curvature.

There have been more basic investigations. For example, using a tandem arrangement of two symmetric airfoils, the confluence between the wake and turbulent boundary layer on the downstream airfoil was investigated in a variable pressure gradient environment by Bario, Charnay and Papailiou ${ }^{4}$. Additional fundamental studies of confluent boundary layers have been performed and reported in a series of papers by the group at Cambridge University (Zhou and Squire ${ }^{5,6}$, Agoropoulos and Squire $^{7}$ and Moghadam and Squire ${ }^{8}$ ). These experiments have primarily examined the interaction between a wake generated by either a flat plate or symmetric airfoil and the neighboring wind tunnel wall boundary layer. In each case both the airfoil and tunnel wall boundary layers were artificially tripped to produce turbulent flow. Such studies have shown that the level of turbulence in the wake has a very strong influence on the wake/boundary layer interaction. In cases where there is strong vortex shedding from the wake generating airfoil, the mixing in the interacting flow is found to be quite strong. The resulting confluent boundary layer is much thicker than the turbulent boundary layer would be in the absence of the upstream wake-generating body. Cases such as these also presented the greatest difficulties in computations since they involved counter-gradient momentum transport which violates standard eddy viscosity-based turbulence models. That is, in the initial region of the interaction, the shear stress and mean velocity gradient normal to the wall can have opposite sign which implies that the effective eddy viscosity is negative! Obviously such flows cannot be modeled with any type of standard eddy viscosity model. 
Further, the counter gradient transport tends to occur in the initial stages of the wake/boundary layer interaction which has the effect of "contaminating" numerical solutions obtained via streamwise marching methods. Even in regions without countergradient transport, the nature of the interaction is quite complex and the turbulence model constants are not known a priori. Experiments have also shown that the effect of an adverse pressure gradient on the wake/boundary layer interaction is to accelerate the thickening of the confluent layer. This will obviously have important implications for high-lift systems.

Measurements of confluent boundary layer development in more realistic multielement geometries have been performed in a study by Braden et $\mathrm{al}^{9}$ using a NASA GAW-1 main element airfoil equipped with a 29 percent chord single-slotted trailing flap and 15 percent chord leading edge slat. Flow field measurements for twenty five different combinations of flap/slat deflection and angle of attack were presented in their report. Olson $^{10}$ presents two theoretical methods by which a multi-element airfoil may be optimized for maximum lift production. Supporting experimental measurements are also presented and compared with theoretical predictions.

\section{EXPERIMENTAL FACILITY AND MEASUREMENT APPARATUS}

The confluent boundary layer experiments were performed in an in-draft wind tunnel facility located at the Hessert Center for Aerospace Research at the University of Notre Dame. Ambient air is drawn through a contraction inlet of $9 \mathrm{ft}$. by $9 \mathrm{ft}$. area with a contraction ratio of $20.25: 1$. The test section is $6 \mathrm{ft}$. in length, $2 \mathrm{ft}$. in height and $2 \mathrm{ft}$. in width. To facilitate flow visualization and LDV measurement, one side wall of the test section is made of glass. 


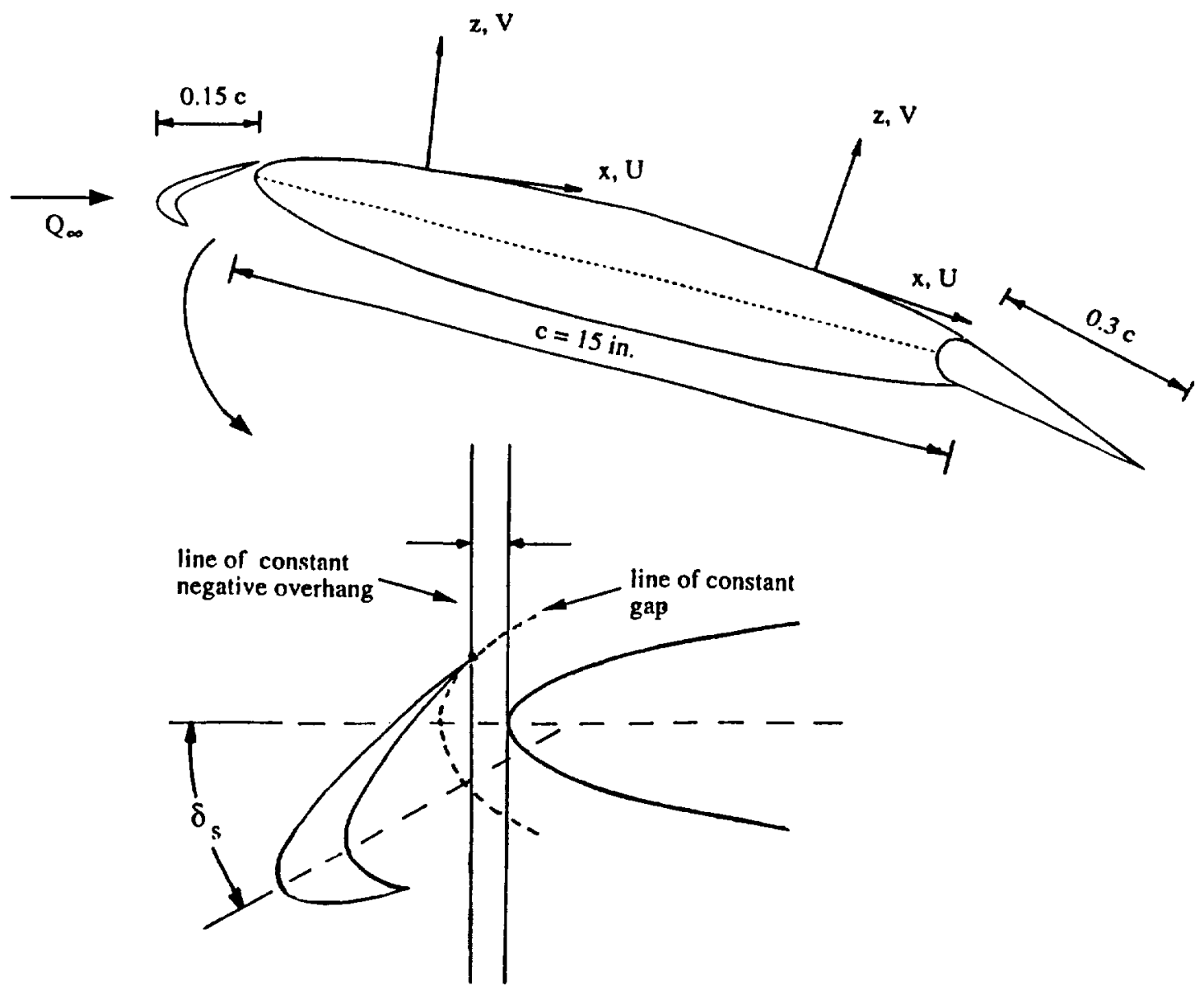

Figure 2. Schematic of the Multi-Element Airfoil Model

A schematic of the high-lift system model is shown in Figure 2. Since the focus of this work is on slat wake / main element confluence, the high-lift system model is a simplified 2-D multi-element airfoil, the main element of which is elliptical with maximum thickness to chord ratio of $15 \%$. A plain tapered flap of $30 \%$ chord length was hinged at the trailing-edge. The purpose of the flap was to provide the same type of "peaked" main element pressure distribution for confluent boundary layer development that occurs in actual high-lift systems. A leading-edge slat, the upper surface of which takes the shape of the leading-edge of the main airfoil, was deployed in front of the leading-edge of the main element. The slat has a cove region on the lower surface that is typical of actual high-lift systems. The position of the slat relative to the main element 
was fully adjustable in terms of angle of attack, gap and overhang. For readers unfamiliar with slat rigging nomenclature, Figure 2 also illustrates representative lines of constant gap and overhang. Unless otherwise noted, the experiments were performed at a stowed chord Reynolds number of nominally 1.1 million. Figure 2 also presents the coordinate system that is used in presenting the measurements. As shown, $\mathrm{x}$ is the streamwise spatial coordinate locally tangent to the main element surface with the corresponding local velocity component denoted $U$. The spatial coordinate locally normal to the main element is $\mathrm{z}$ with corresponding local velocity component $\mathrm{V}$.

In order to facilitate flow visualization of the slat wake-main element boundary layer confluence, both the main element and leading-edge slat contained separate internal plenums connected to thin surface smoke injection slots. A kerosene smoke generator was connected via flexible tubing to both internal plenums. The slot on the main element allowed the injection of smoke into the main element boundary layer near the stagnation point (which was nominally located on the lower surface). The slot on the leading-edge slat allowed injection of smoke into the top surface slat boundary layer and thereby provided a means of visualizing the slat wake. An Argon-ion laser light sheet was positioned in the $\mathrm{x}-\mathrm{z}$ centerspan plane of the model in order to illuminate the smoke and visualize the confluent boundary layer. In order to obtain integrated lift, a second identical multi-element airfoil model was used which contained numerous static pressure taps on the upper and lower surfaces of the slat, main element and trailing flap. The multielement airfoil model nearly spanned the test section and was installed in the wind tunnel with transparent end plates. Spanwise arrays of pressure taps confirmed that the flow over the model was nominally two-dimensional. 
Transition was allowed to occur naturally as no surface grit or boundary layer trips were used. The LDV measurements to be presented in the following sections indicate the boundary layer on the main element to be turbulent by the first chordwise measurement station which was near $x / c=0.06$. Hot-wire surveys indicated the boundary layer on the slat top surface just upstream of the trailing-edge to be transitional. Flow visualization revealed the flow in the slat cove region to be separated and turbulence intensities measured in the near wake immediately downstream of the slat lower surface indicate fluctuation intensity levels approaching $23 \%$ (referenced to the local external velocity, $\mathrm{U}_{\mathrm{e}}$ ). However, power spectra show that most of this energy resides in discrete modes that are most likely associated with the shedding of vortices from the slat. This aspect will be discussed in more detail section 4 of the report which focuses on the unsteady aspects of high-lift flows.

The detailed flow structure of the confluent boundary layer was investigated by means of two component LDV surveys at selected chordwise locations. An Aerometrics three-component, fiber optic LDV system was operated in two-component backscatter mode using an Argon-ion laser. Frequency shifting was used in order to unambiguously resolve flow direction. Measurements were made at the center span location for a variety of selected chordwise locations. The measurements were made in the coincident mode and results for both mean flow and turbulence quantities presented in this paper represent ensemble averages over at least 10,000 valid coincident events. A seed particle generator using a mixture of one part Propylene Glycol to three parts distilled water was used to seed the flow at the tunnel inlet. The seed particle generator produces droplets that are nominally in the $1-2$ micron range. The transceiver of the LDV system was mounted to a 
computer controlled traverse table. The accuracy of the movement of the traverse table in horizontal and vertical directions is $0.4 \mu \mathrm{m}$. The $514 \mathrm{~nm}$ and $488 \mathrm{~nm}$ laser wavelengths were used to measure the $\mathrm{U}$ and $\mathrm{V}$ components, respectively. The diameter of the LDV measurement volume, which is the limiting factor in setting the spatial resolution in the zcoordinate, is $239 \mu \mathrm{m}$.

The focus of the experiments described in this report is on the flow physics of the slat wake / main element confluent boundary layer and the role that confluence plays on lift production in high-lift systems. For this reason, the geometric angle of attack and trailing-edge flap deflection were held fixed in the experiments while the leading-edge slat gap and overhang were then varied over a range of positions. It was found that a main element geometric angle of attack of 10 degrees and a trailing-edge flap deflection of 13 degrees represented a good compromise in terms of producing a surface pressure distribution on the model similar to those encountered in actual commercial high-lift systems while minimizing the effects of tunnel blockage. The slat was positioned at an attack angle of -10 degrees so that it faced directly into the approach flow. Even at the modest angle of attack quoted above, however, the tunnel blockage was still $15 \%$. In order to assess the effect of blockage, tests were also performed in a larger in-draft tunnel at Hessert Center with a $5 \mathrm{ft}$. by $5 \mathrm{ft}$. cross-sectional area for which the blockage was only $2.4 \%$. It was found that standard blockage corrections could be applied to the $2 \mathrm{ft}$. by $2 \mathrm{ft}$. test section data to correct the results to match those in the larger tunnel. In addition, it was found that the blockage effect resulted in higher effective angles of attack for the model in the smaller facility. Perhaps most important for the purposes of this investigation, however, was the observation that integrated lift coefficients showed the 
same trends with variation in slat gap and overhang in both facilities. Since our purpose was simply to provide a realistic pressure gradient environment for the confluent boundary layer to develop and not to produce lift data for extrapolation to flight, the blockage issue was not a significant factor.

\section{EXPERIMENTAL RESULTS}

\subsection{Summary of Flow Visualization and Integrated Lift Results}

Even with the orientation of the model and flap position fixed, this still left a fairly large parameter space in terms of slat gap and overhang. In order to reduce the parameter space for detailed LDV study, integrated lift and confluent boundary layer flow visualization was first performed for a variety of slat overhang and gap settings. The variation of lift (based on numerically integrated surface pressure distributions) with slat position is shown in Figure 3. In this figure the integrated lift is denoted as $\mathrm{C}_{\text {ltotal }}$ and is normalized by the lift coefficient obtained with the slat fully stowed which is denoted as $\mathrm{C}_{\text {lo }}$. This normalization shows the relative change in lift coefficient with slat gap and overhang variations. In this figure the lift measurements are presented as shaded contours in slat gap - overhang parameter space. Both the slat gap and overhang are expressed as percentages of the stowed chord length. Lighter shading indicates the highest relative lift coefficient. Note that optimum lift is obtained for a quite narrow range of slat gap values and that lift falls off for both sufficiently large and small slat gap settings. Figure 3 shows that the lift also falls off with negative overhang. These data show what has been observed in design tests of multi-element airfoils; that the performance of the high-lift system can be quite sensitive to slat position relative to the main element. 


\section{Nondimensional Lift Coefficient Contour Plot}

. (Flap at 13 degree; $\mathrm{Cl}_{\text {total }} / \mathrm{Cl}_{0} ; \mathrm{Cl}_{0}=1.484$ )

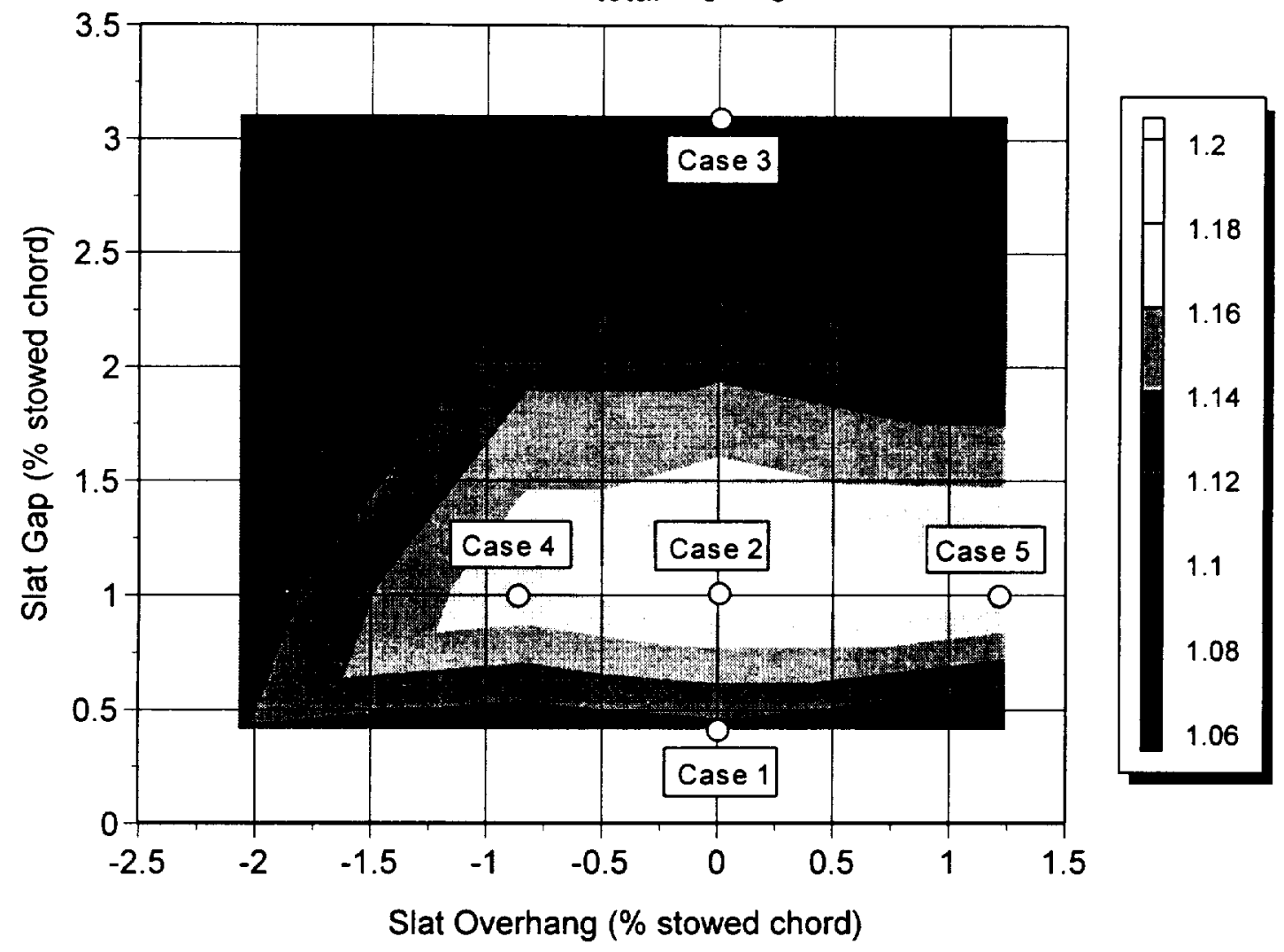

Figure 3. Lift Coefficient Contours in Slat Gap -Overhang Parameter Space.

In order to clarify the role of the leading-edge confluent boundary layer on this variation in lift, smoke injection flow visualization was performed at several of the slat gap and overhang combinations indicated in Figure 3 and some of the results are qualitatively summarized in sketches shown in Figure 4. Case numbers correspond to those shown in Figure 3. Figure 4a presents case 3 which corresponds to zero overhang and a slat gap of $3.1 \%$ stowed chord. At this comparatively large slat gap setting, the surface pressure measurements (not presented) show that the slat is unloaded and is there- 


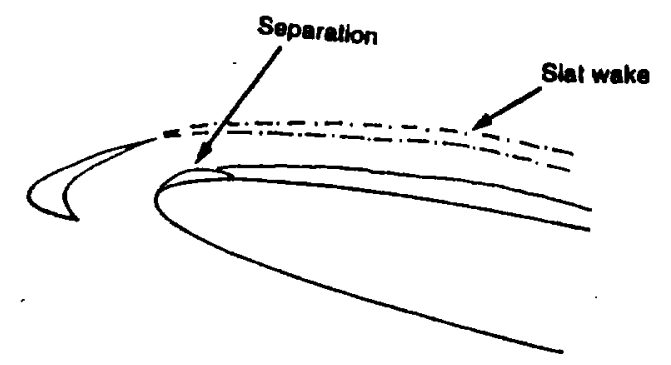

a. Case 3
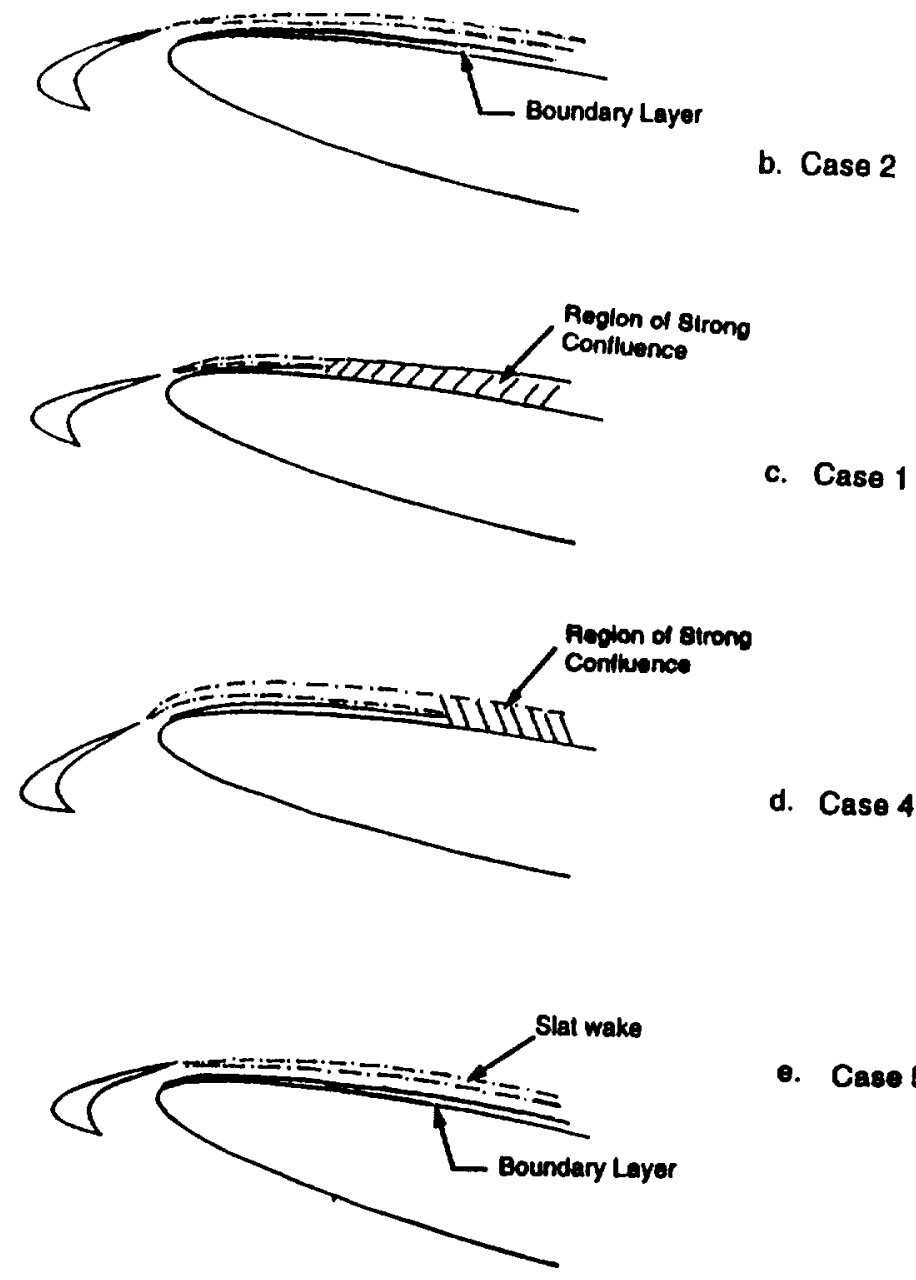

9. Case 5

Figure 4. Summary Sketches of Flow Visualization Results.

fore ineffective at moderating the surface pressure on the leading-edge of the main element. As a consequence, a large separation bubble is observed on the main element and the lift is reduced. Figure $4 \mathrm{~b}$ presents Case 2 which corresponds to zero overhang and a $1 \%$ gap setting. This configuration is near optimum in terms of lift production. Here, the 
flow visualization shows the slat wake and boundary layer to be separated and strong confluence is apparently delayed until the most aft chordwise stations. Figure $4 \mathrm{c}$ presents a sketch of Case 1 which corresponds to zero overhang and $0.4 \%$ gap. This case represents the smallest slat gap setting investigated. Although pressure measurements indicate that the slat remains highly loaded as in Case 2, Figure $4 \mathrm{c}$ suggests that strong confluence between the slat wake and main element boundary layer occurs and lift production is adversely affected. Figure $4 \mathrm{~d}$ corresponds to Case 4 which has the same gap setting as in Case 2 but a negative overhang of $-0.83 \%$. In this case, pressure measurements indicate that the slat is not highly loaded and the flow visualization indicates a vertical jetting of the wake near the trailing-edge. The main element boundary layer, while remaining attached, grows in a strong adverse pressure gradient environment. Strong confluence is observed upstream of the mid-chord position. Finally, Figure $4 \mathrm{e}$ presents Case 5 which correspond to $1.2 \%$ overhang and $1 \%$ gap. As in case 2, the slat is highly loaded and moderates the main element nose pressure peak. The slat wake and boundary layer confluence is delayed until well downstream yielding favorable lift behavior.

In summary, Figure 4 shows that optimum lift behavior is associated with cases for which strong slat wake/main element boundary layer confluence is delayed. In contrast, for Case 1, although the slat remains loaded, the gap is so small that the location of strong confluence moves forward and lift production is adversely affected. In Case 4, the slat is not highly loaded but again early confluence occurs and is associated with diminished lift. Case 3 simply corresponds to a case in which confluence is not the key issue but rather, the slat is ineffective due to the large gap setting. 


\subsection{Confluent Boundary Layer LDV Flow Field Surveys}

Detailed two-component LDV surveys of the confluent boundary layer on the highlift model were performed. The objectives of these measurements were to: (1) gain insight into the relevant flow field physics of confluent boundary layer structure and development in both pressure gradient environment and geometric conditions similar to those in actual high-lift systems and relate this to the integrated lift behavior of the highlift model, (2) to provide a detailed archival data base for turbulence modeling and comparison with CFD simulation.

Complete flow surveys were performed for a variety of the slat gap and overhang settings shown in Figure 3. Space limitations prevent presentation of all these results here. Instead we choose to focus on a comparison of confluent boundary layer flow field surveys for case 2 (which corresponds to a near-optimum slat setting) and case 1 which involves early onset of confluence due to the reduced gap setting. It is important to point out that in both cases the slat is highly loaded so that the reduction in lift shown in Figure 3 for case 1 is a consequence of the forced early confluence.

Results from the additional LDV flow field surveys will be made available by the authors in disk format upon request. In presenting the LDV measurements for cases 1 and 2 , we will first discuss the mean flow development followed, in turn, by turbulence quantities.

\subsubsection{Mean Flow Development for Cases 1 and 2}

Figure 5 presents mean velocity profiles, $\mathrm{U}(\mathrm{z}) / \mathrm{U}_{\mathrm{e}}$ for cases 1 and 2 as obtained at several representative chordwise locations on the main element. Here $U_{e}$ is the local velocity outside the viscous layer and is, of course, a function of $x / c$. At $x / c=0.1$ the 
slat wake is clearly visible and close inspection shows it to be asymmetric in shape for both cases. The wake and boundary layer are clearly separated at this chordwise location for case 2 . In case 1 , however, mixing between the wake and boundary layer has already commenced at $\mathrm{x} / \mathrm{c}=0.1$. This mixing of the boundary layer and wake is well underway by $x / c=0.3$ and, as a consequence, the case 1 flow is retarded near the wall in relation to case 2. This trend is observed to continue for each $\mathrm{x} / \mathrm{c}$ location investigated and appears associated with the early onset of confluence between the slat wake and boundary layer. Figure 5 does show evidence of onset of weak confluence for case 2 at the $\mathrm{x} / \mathrm{c}=0.3$ location. Figure 5 suggests a more aggressive mixing between the slat wake and main element boundary layer for Case 1.

Figure 5 also illustrates another interesting difference between the mean flow data of cases 1 and 2. Each datum point in this figure is based on an ensemble average over at least 10,000 valid LDV burst events. As a result, the case 2 profiles are quite smooth and exhibit very little scatter. In contrast, despite the long effective averaging times used for the measurements, the case 1 profiles of Figure 5 show considerable scatter, especially in the outer wake region. This scatter was traced to unsteady flow behavior originating in the slat cove region. Further discussion of this aspect will be deferred to section 4 which presents a detailed discussion of unsteady aspects of the high-lift flow.

Despite the apparent differences between the confluent boundary layer profiles shown in Figure 5 and those of conventional turbulent boundary layers, it is important to point out that in each case it was found that sufficiently close to the wall the profiles exhibit classic log law of the wall turbulent boundary layer scaling behavior. In order to 


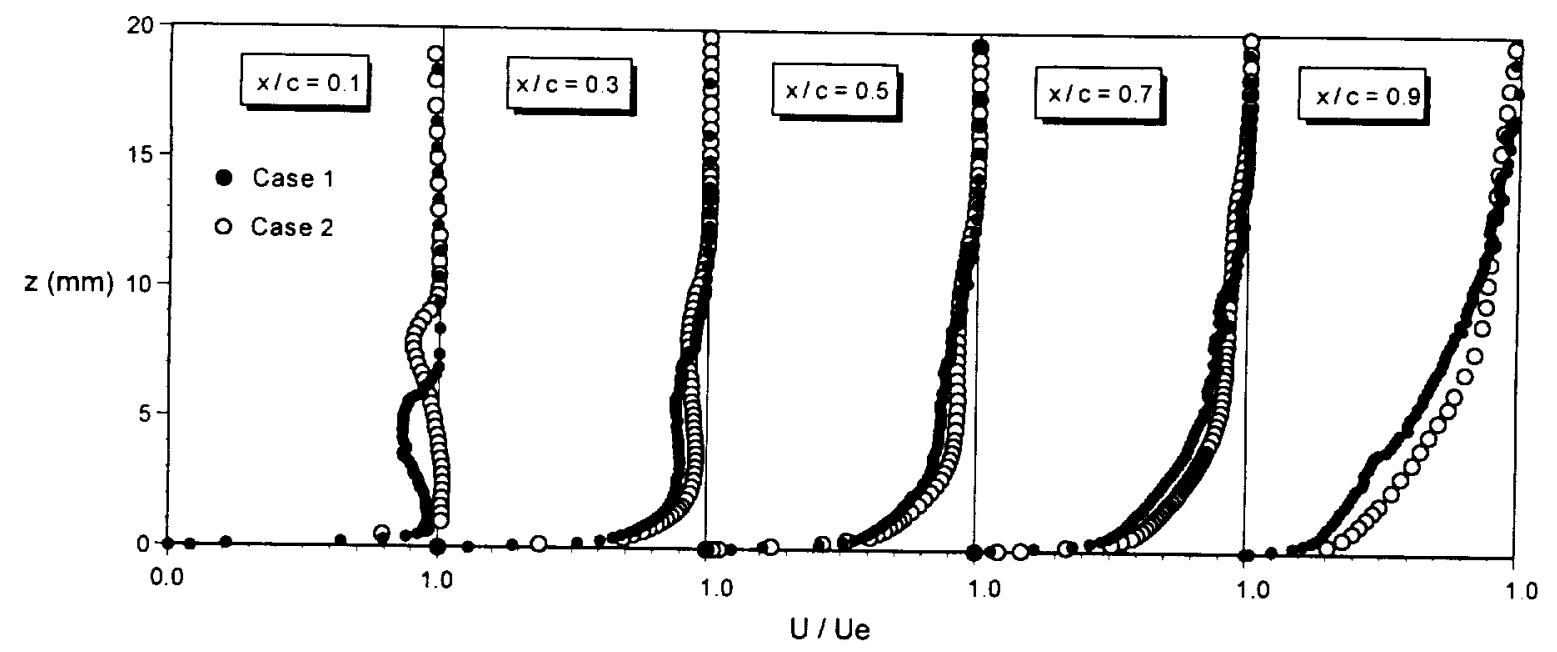

Figure 5. Comparison of Case 1 and Case 2 Mean Velocity Profiles

apply inner variable scaling, the local skin friction was estimated using both the Clauser method and Preston tube measurements. Although these methods both assume log law behavior, plots of $U / U_{e}$ versus $\ln \left(U_{e} z / v\right)$ each show the presence of a well-defined logarithmic region near the wall. Further, the inner variable scaling of the profiles using the experimentally obtained values of skin friction did indeed yield profiles with a logarithmic region of form $\mathrm{u}^{+}=(1 / \kappa) \ln \mathrm{z}^{+}+\mathrm{B}$ with $\kappa=0.41$ and $\mathrm{B}=5$. Here $\mathrm{u}^{+}=\mathrm{U} / \mathrm{u}_{\tau}$ and $\mathrm{z}^{+}=\left(\mathrm{z}_{\tau}\right) / v$, where $\mathrm{u}_{\tau}$ is the friction velocity and $v$ the kinematic viscosity. Example confluent boundary layer profiles for cases 1 and 2 using inner variable scaling are shown in Figure 6a,b. The log-law-of-the-wall is shown as a solid line. Note that the case 1 profile shows that the unsteady activity (as evidenced by scatter in the datum points) is confined to the wake region of the profile while that portion near the wall exhibits comparatively little scatter. 


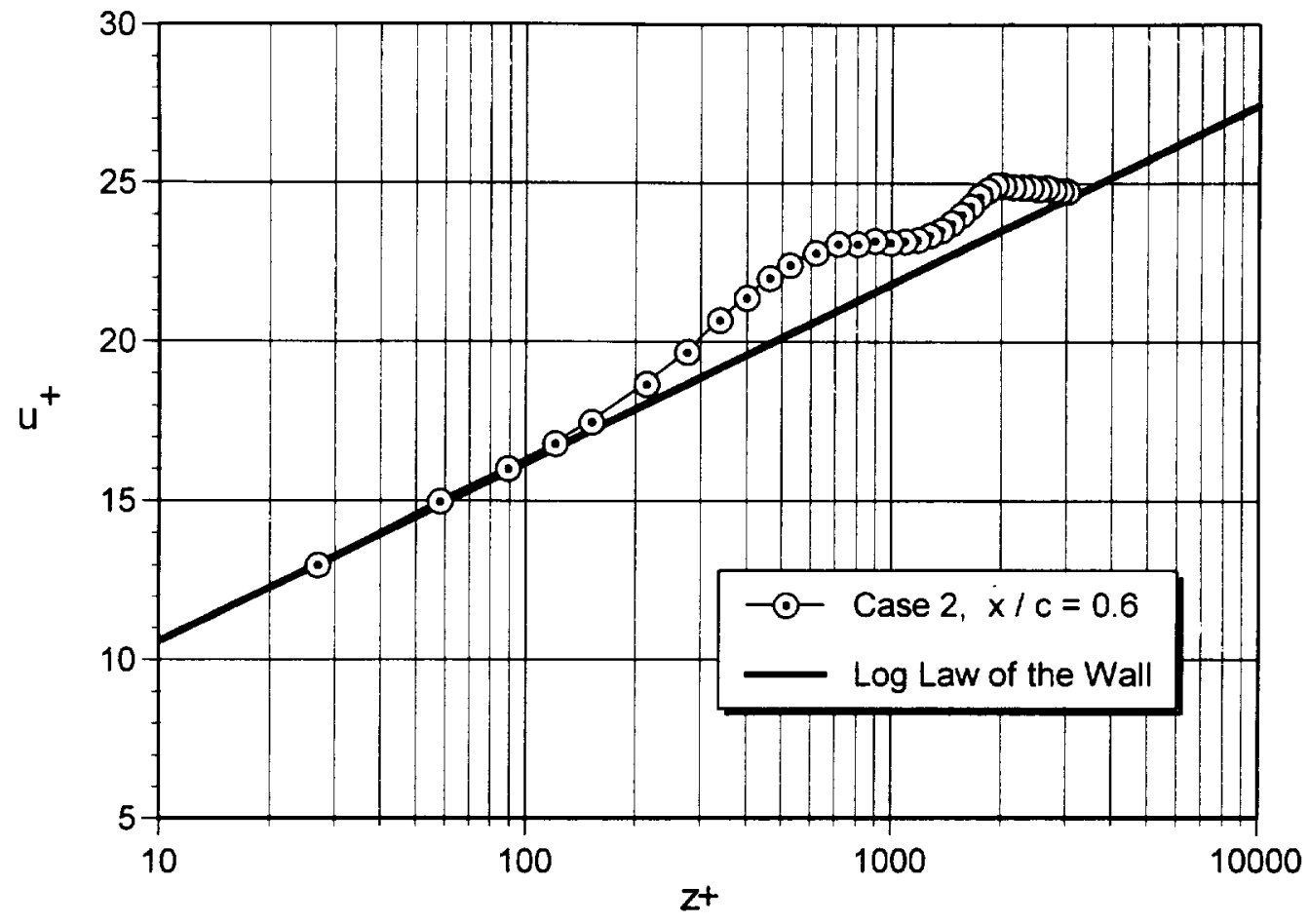

Figure 6a. Inner Variable Scaling of Mean Velocity: Case 2, $x / c=0.6$

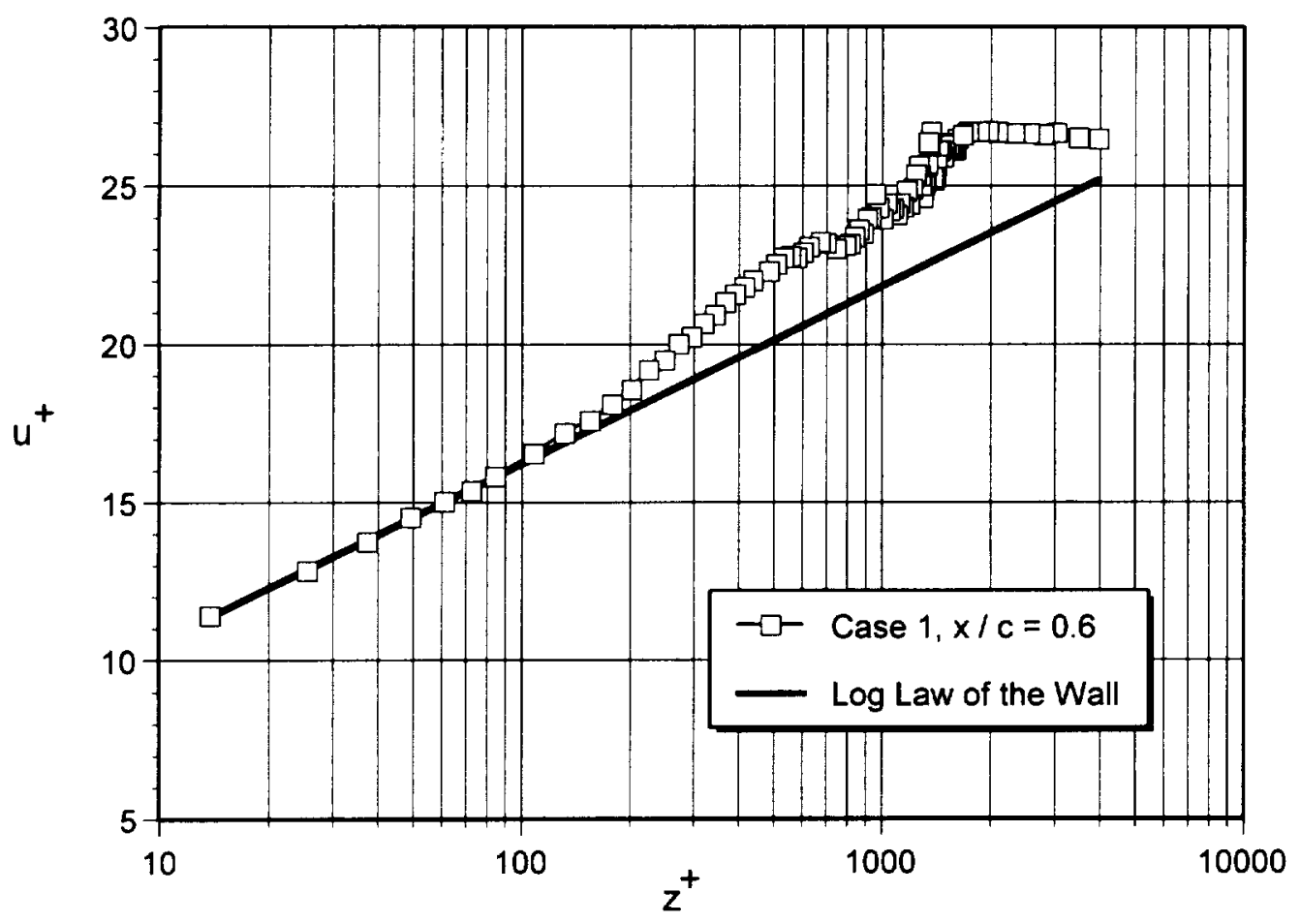

Figure 6b. Inner Variable Scaling of Mean Velocity: Case 1, $x / c=0.6$ 
Alternatively, outer law velocity defect scaling may be employed in the presentation of the confluent boundary layer profiles and the results for case 2 are presented in Figure 7. In this scaling, it becomes apparent that confluence commences between $x / c=0.2$ and 0.3 as Figure 7 shows the development of nonzero velocity defect separating the near wall and outer wake portions of the profile. Note that with the exception of the $\mathrm{x} / \mathrm{c}=0.9$ location, each of the profiles exhibit a reasonable collapse for $z / \delta>0.65$. Inside this region, the defect is observed to grow with streamwise distance.

For a turbulent boundary layer, the momentum defect decreases monotonically with $z / \delta$. For the confluent boundary layer at a given chordwise location, the existence of a range of $\mathrm{z}$ for which the velocity defect increases with distance from the wall is evidence of the presence of the slat wake and indicates that it has not fully mixed with the boundary layer and maintains some semblance of a separate identity. Hence one criterion (but certainly not the only one) for estimating where strong slat wake / boundary layer mixing commences is based upon the chordwise location where the profiles first fail to exhibit any region where the velocity defect grows with distance from the wall. Based upon this criterion, Figure 7 would suggest that for case 2 , "full confluence" is reached by $\mathrm{x} / \mathrm{c}=0.7$. Note that shortly thereafter, the profiles exhibit very large changes in character with the defect near the wall growing very quickly.

Figure 8 presents the streamwise variation of the normalized velocity defect at selected representative $\mathrm{z} / \delta$ locations across the confluent layer for case 2 . This figure serves to further illustrate that in the outer portion of the confluent layer (say, $\mathrm{z} / \delta>0.4$ ) 


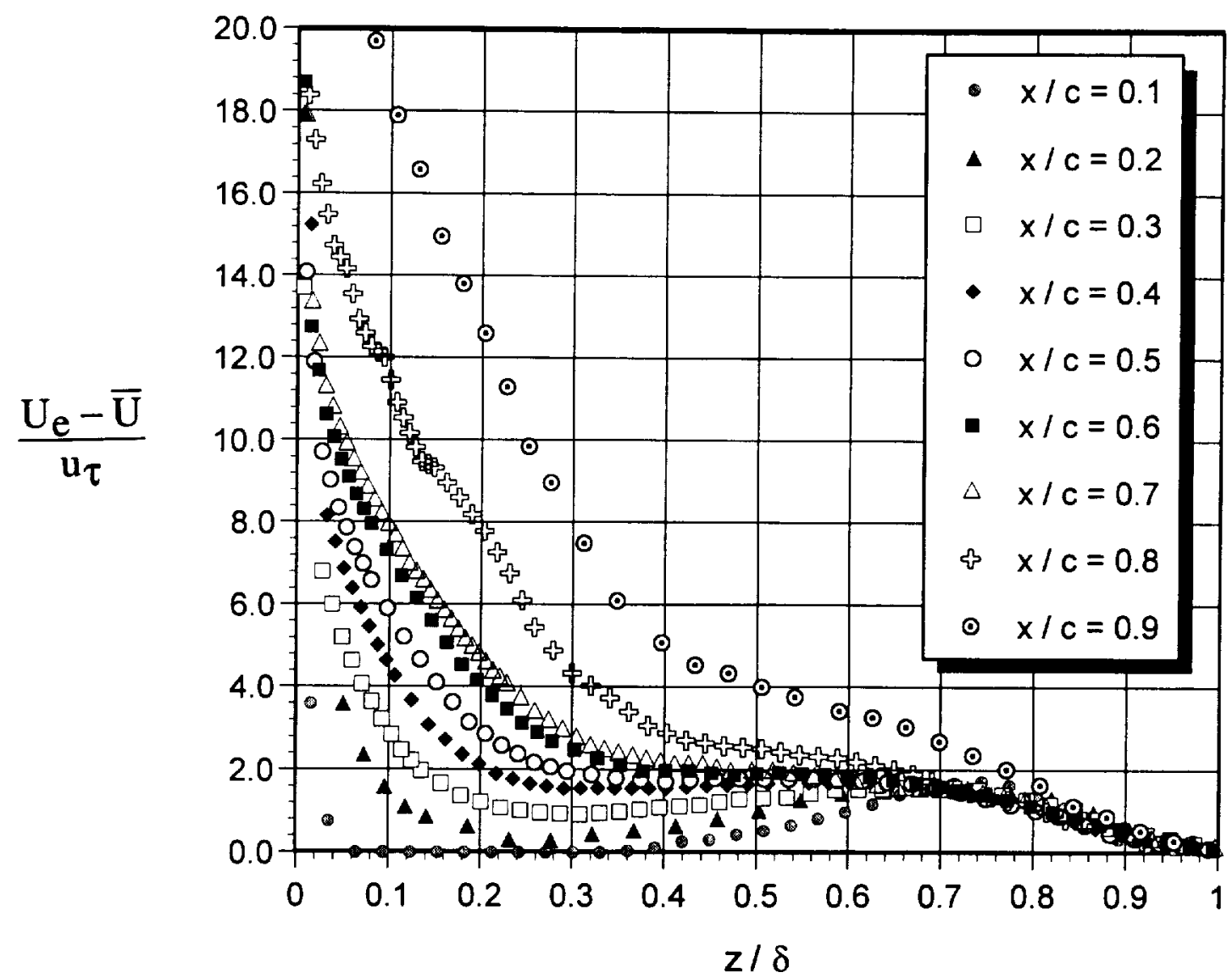

Figure 7. Velocity Defect Scaling of Case 2 Mean Velocity Profiles.

the defect exhibits comparatively little streamwise variation while strong streamwise variation is apparent closer to the wall.

How do the velocity defect profiles shown in Figure 7 compare with those of a turbulent boundary layer in a similar pressure gradient environment? One way to explore this question is to compare the profiles of Figure 7 with the empirical turbulent boundary layer profile of Coles ${ }^{11}$ which, in terms of velocity defect is given by,

$$
\frac{U_{e}-\bar{U}}{u_{\tau}}=-\frac{1}{\kappa} \ln \left(\frac{z}{\delta}\right)+\frac{\Pi}{\kappa}\left[2-w\left(\frac{z}{\delta}\right)\right]
$$




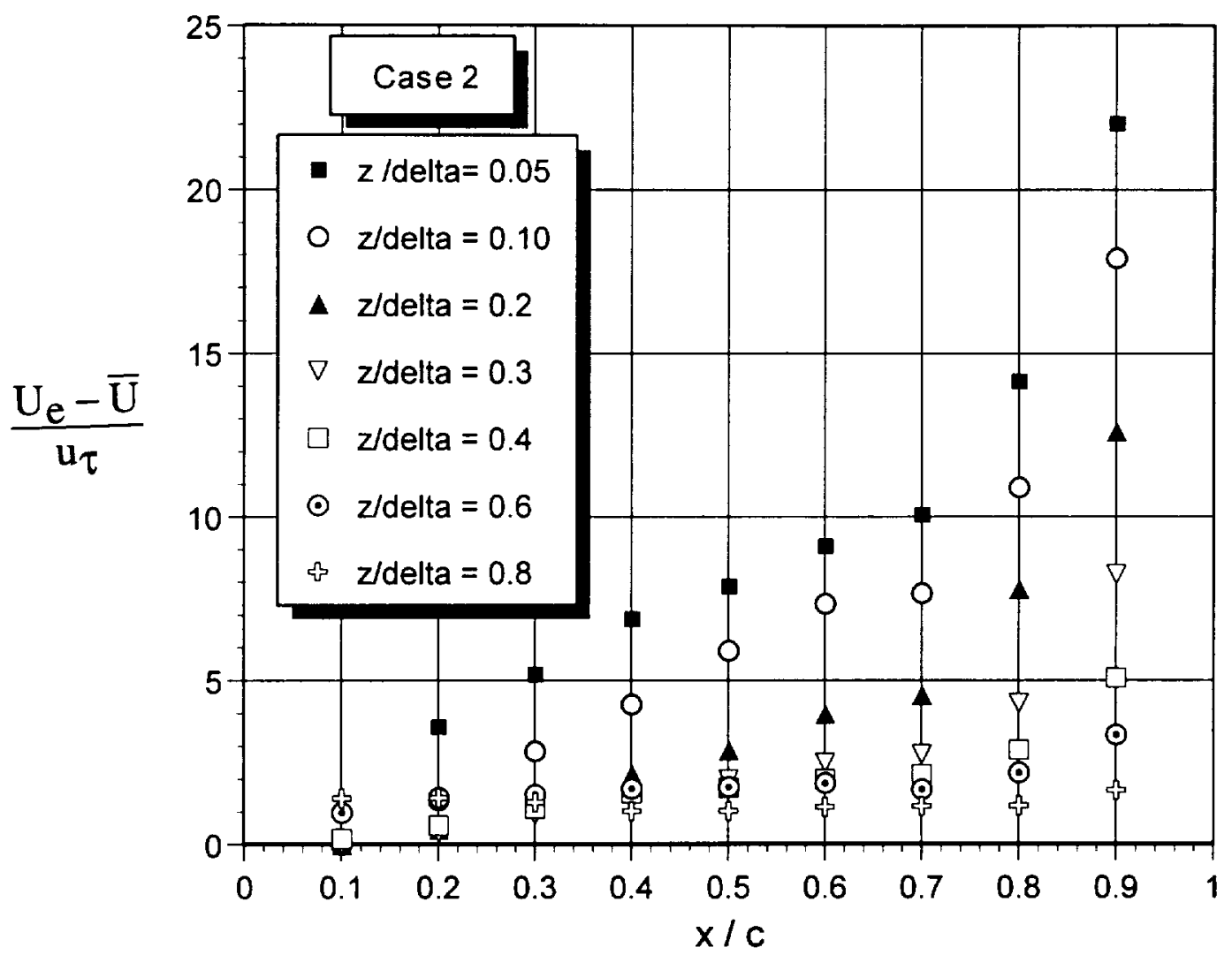

Figure 8. Streamwise Variation in Non-Dimensional Velocity Defect at Selected Wall Normal Locations for Case 2

where $w(z / \delta)$ is the well known "law-of-the-wake" function which experiments show possesses a universal character and $\Pi(\mathrm{x})$ is a profile parameter which depends on pressure gradient. Since $\Pi$ can be related to the local skin friction coefficient, it is possible to provide a suitable value corresponding to each of the profiles shown in Figure 7. As an example, Figure 9 compares the case 2 confluent boundary layer profile at $x / c=$ 0.6 with the corresponding velocity defect profile for a turbulent boundary layer with the same profile parameter, $\Pi$. This comparison (and others that aren't presented) reveals that over a large portion of the confluent boundary layer the velocity defect is less than 


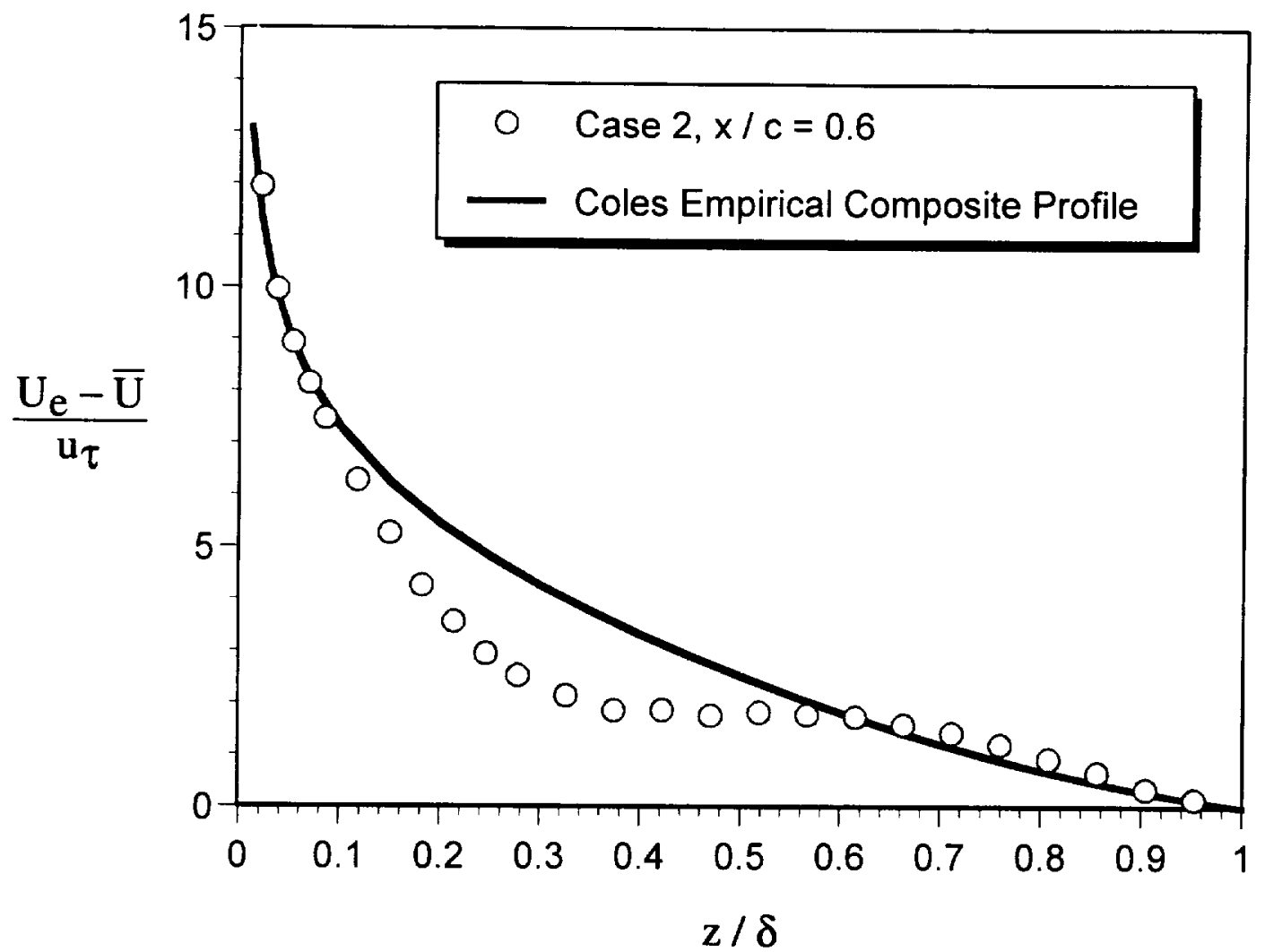

Figure 9. Comparison of Conventional and Confluent Boundary Layer Profiles.

that which occurs in the turbulent boundary layer at a corresponding location above the wall. This is another manifestation of the slat wake interacting with the wall layer.

Figure 10 presents the streamwise variation in mean velocity defect profiles corresponding to case 1 . In this case it is apparent that the slat wake and boundary layer have begun to merge by $\mathrm{x} / \mathrm{c}=0.1$ and appear completely mixed by $\mathrm{x} / \mathrm{c}=0.4$ as evidenced by a continuous decrease in velocity defect with $z$. The collapse observed in case 2 for $z / \delta$ $>0.7$ is not so apparent here as a consequence of the scatter which is a manifestation of the previously described unsteady behavior in the wake. 


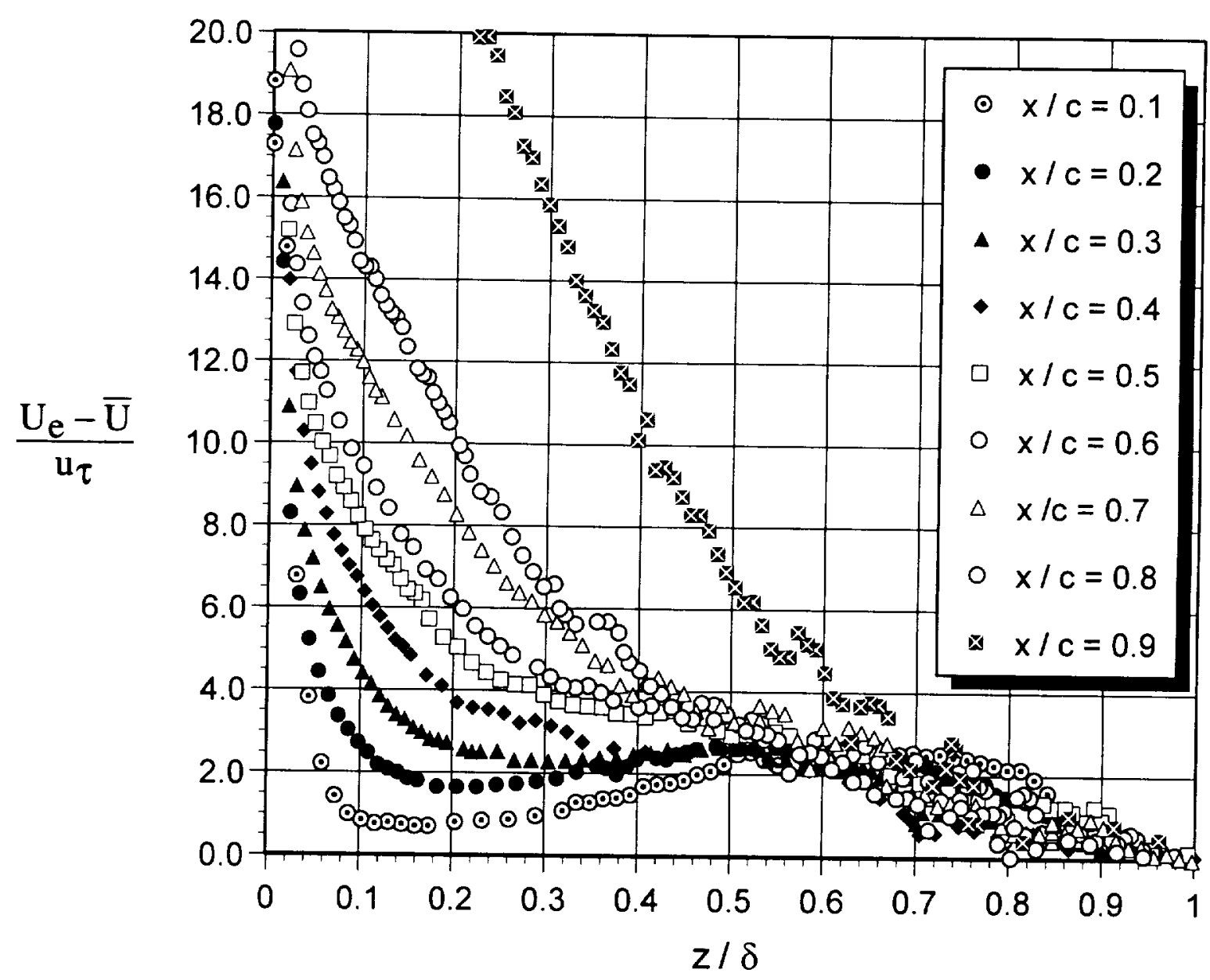

Figure 10. Velocity Defect Scaling of Case 1 Mean Velocity Profiles.

Figure 11 compares the chordwise variation of displacement thickness for cases 1 and 2. This figure is derived from integration of mean flow profiles like those presented in Figure 5. Figure 11 shows that at each chordwise station the case 1 displacement thickness exceeds that for case 2 as is consistent with the case 1 flow being more severely retarded near the wall in relation to its case 2 counterpart. Due to the associated outward 


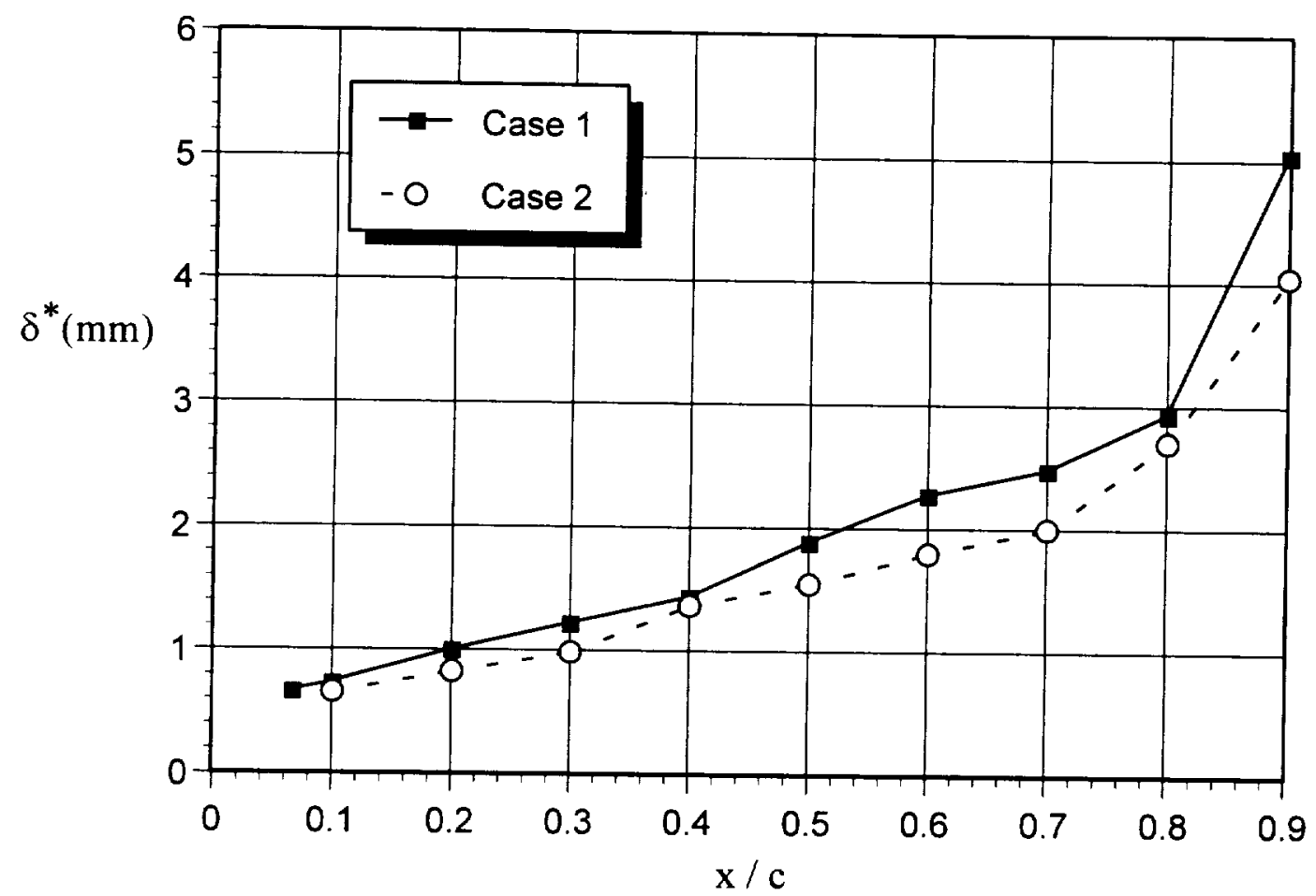

Figure 11. Chordwise Variation in Displacement Thickness for Case 1 and 2.

streamline displacement, this will have the effect of reducing the suction pressure on the main element so that even in the absence of separation, lift will be adversely affected.

Figure $12 \mathrm{a}, \mathrm{b}$ presents $\overline{\mathrm{V}} / \mathrm{U}_{\mathrm{e}}$, the normalized mean, locally normal velocity component for cases 1 and 2 as obtained at two representative chordwise locations. Figure 12a compares the $\overline{\mathrm{V}} / \mathrm{U}_{\mathrm{e}}$ profiles at $\mathrm{x} / \mathrm{c}=0.2$. Both case 1 and 2 profiles show a region of negative $\bar{V}$ near the wall although in both cases $\bar{V}$ approaches 0 at the wall as required by the no slip condition. A qualitative sketch showing how the resulting $\bar{V}$ profile shape comes about is shown in Figure 12c. As shown qualitatively in the sketch, the region of negative $\bar{V}$ in Figure 12a is a manifestation of downwash from the upstream slat superimposed upon a $\bar{V}$ component which grows with $\mathrm{z}$ as a consequence 
of the displacement of streamlines away from the wall due to the viscous layer (see Figure 11). Note also that the "S" shaped variation in $\bar{V}$ farther above the wall is a consequence of the entrainment flow associated with the slat wake.

The $\bar{V} / U_{e}$ profiles at $x / c=0.6$ show a reduction in the peak negative $\bar{V}$ near the wall consistent with the increased distance from the slat. Keep in mind that $U_{e}$ is also reduced at this location so the reduction is actually greater than indicated. The $\bar{V}$ variation associated with the slat wake entrainment flow is not so apparent at this location due to the considerable mixing that has taken place between the wake and the wall layer. At a given $z$, the $\bar{V}$-values for case 1 exceed those for case 2 consistent with the case 1 flow being more strongly retarded near the wall and exhibiting greater displacement thickness values.

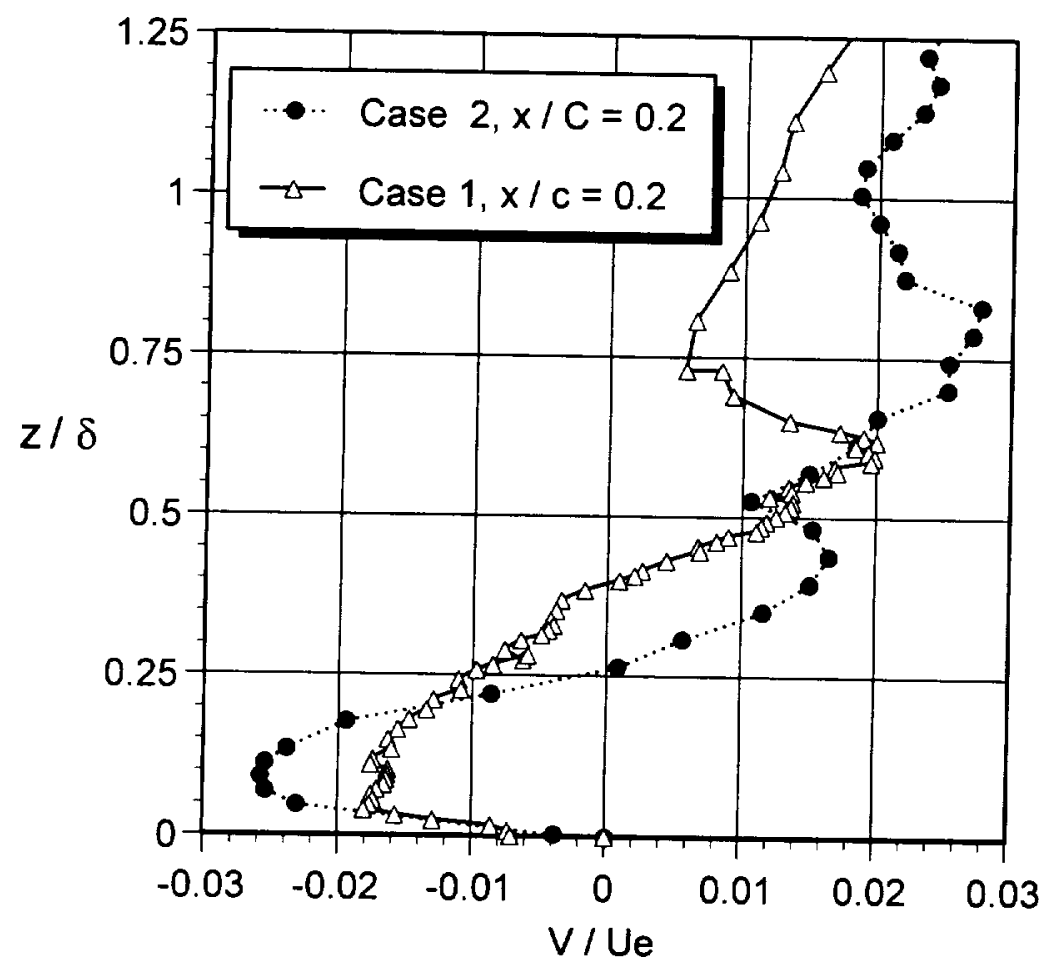

Figure 12a. Local Normal Component Mean Velocity Profiles at $\mathbf{x} / \mathbf{c}=\mathbf{0 . 2}$. 


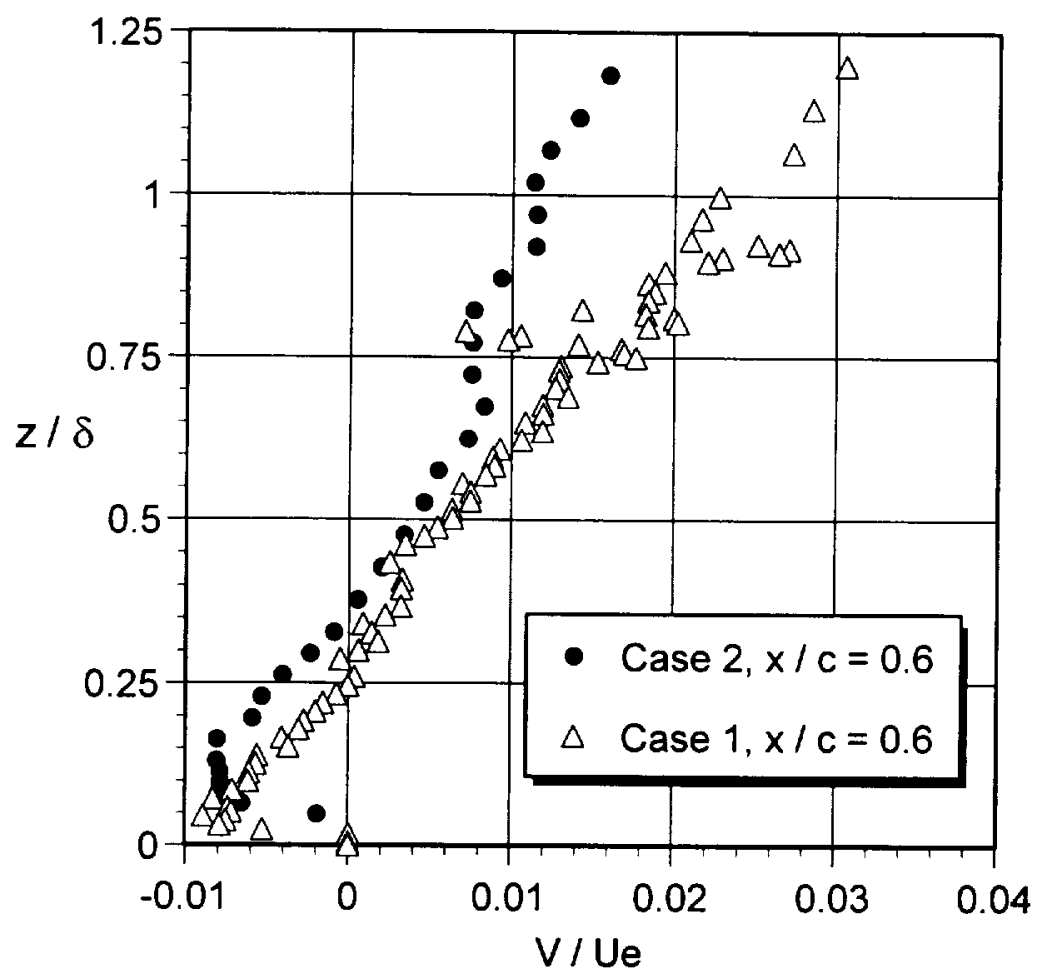

Figure 12b. Local Normal Component Mean Velocity Profiles at $\mathbf{x} / \mathbf{c}=\mathbf{0 . 6}$.
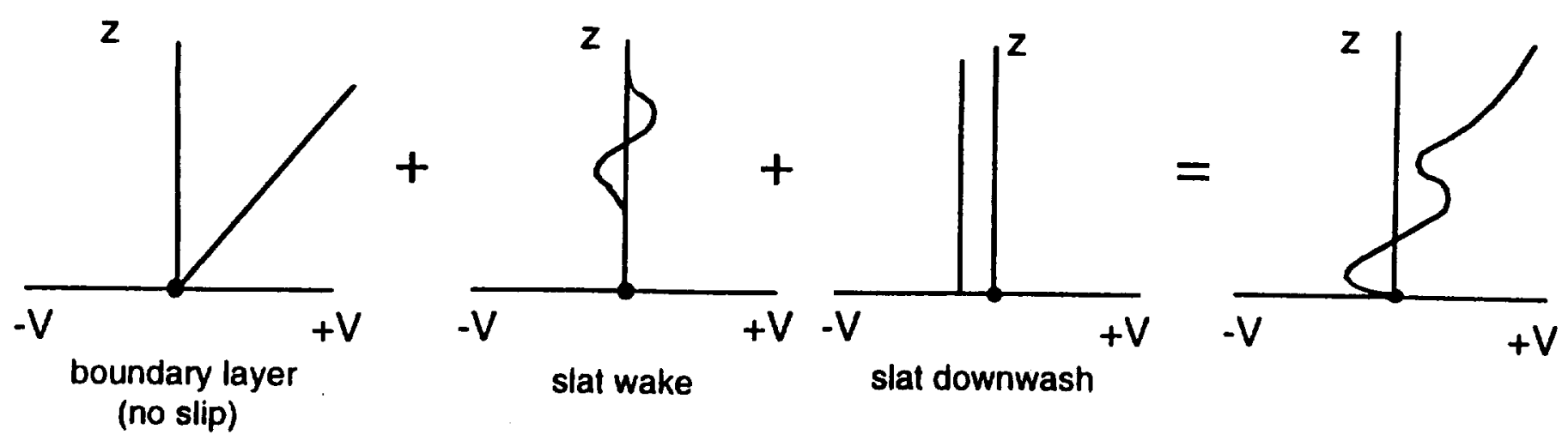

Figure 12c. Schematic Showing Origin of V Profile Shape. 


\subsubsection{Turbulence Quantities for Cases 1 and 2}

Figure 13 presents profiles of the local tangential and normal component turbulence intensities as obtained at representative chordwise locations on the main element for Case

2. At each $\mathrm{z}$ location within the viscous layer $\sqrt{\overline{\mathrm{u}^{\prime 2}}} / \mathrm{U}_{\mathrm{e}}$ is observed to be greater than $\sqrt{\overline{\mathrm{v}^{\prime 2}}} / \mathrm{U}_{\mathrm{e}}$. This is to be expected since the Reynolds stress working against the mean velocity gradient will feed energy into the tangential $u^{\prime}$ fluctuating component first. A portion of this energy will then be redistributed to the other components by the convective diffusion terms of the turbulence kinetic energy equation. Outside the viscous layer the $u^{\prime}$ and $v^{\prime}$ intensities are approximately equal due to the fact that the background turbulence in the wind tunnel is approximately isotropic. At each chordwise station shown, peak u' intensity occurs very near the wall and the $u^{\prime}$ intensity profile changes little with $x / c$ for $z / \delta<0.10$. The peak $u^{\prime}$ intensity near the wall at each location is $10-11 \%$; values which are typical of turbulent boundary layers in general. Peak $v^{\prime}$ intensity values are between $4 \%$ and $5 \%$. In contrast to the inner region of the viscous layer, the $u^{\prime}$ and $v^{\prime}$ turbulence intensities in the outer part of the confluent layer are observed to undergo large changes with $x / c$. In particular, both the $u^{\prime}$ and $v^{\prime}$ turbulence intensities in the region of $z / \delta$ which the mean velocity profiles indicate to be associated with the slat wake are observed to decay with $\mathrm{x} / \mathrm{c}$. This is likely due to the reduction in mean shear as the slat wake mixes with the boundary layer and gradually loses its identity. There is also a growth in $\mathrm{u}^{\prime}$ and $\mathrm{v}^{\prime}$ component intensities for $z / \delta$ between the outer wake and near wall regions, apparently associated with the transport of turbulence away from the wall and toward the outer portion of the confluent boundary layer. 

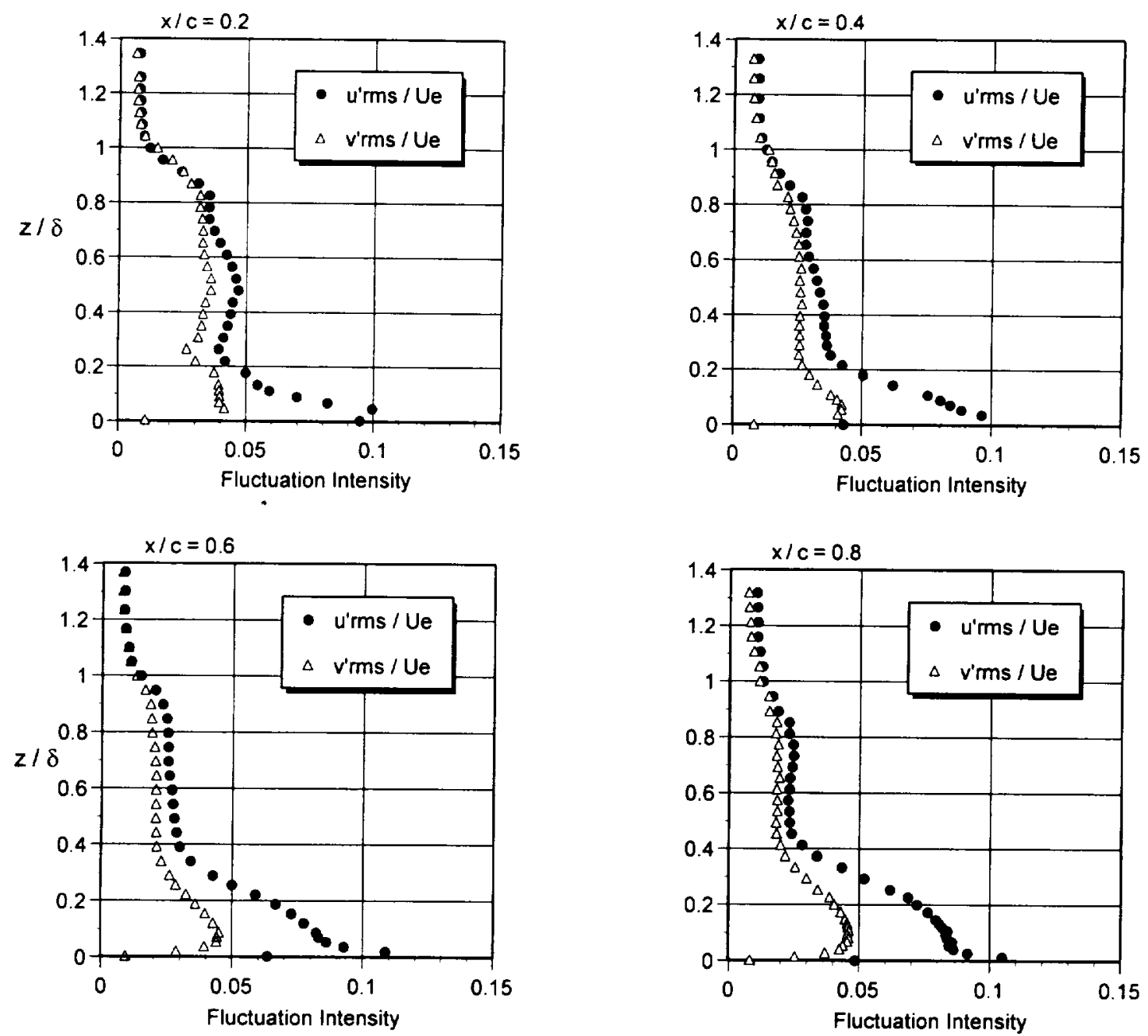

Figure 13. Tangential and Normal Component Turbulence Intensities for Case 2.

Figure 14 presents $u^{\prime}$ and $v^{\prime}$ component intensity profiles for Case 1. The biggest difference between these data and case 2 is that the $u^{\prime}$ intensity near the wall is considerably higher for case 1 . Further, this intensity is greatest at small $\mathrm{x} / \mathrm{c}$ and decays gradually with chordwise distance to eventually reach $u^{\prime}$ intensity values near the wall of approximately $10 \%$ as in case 2 . Note that the abscissa scale for the intensity profiles at 

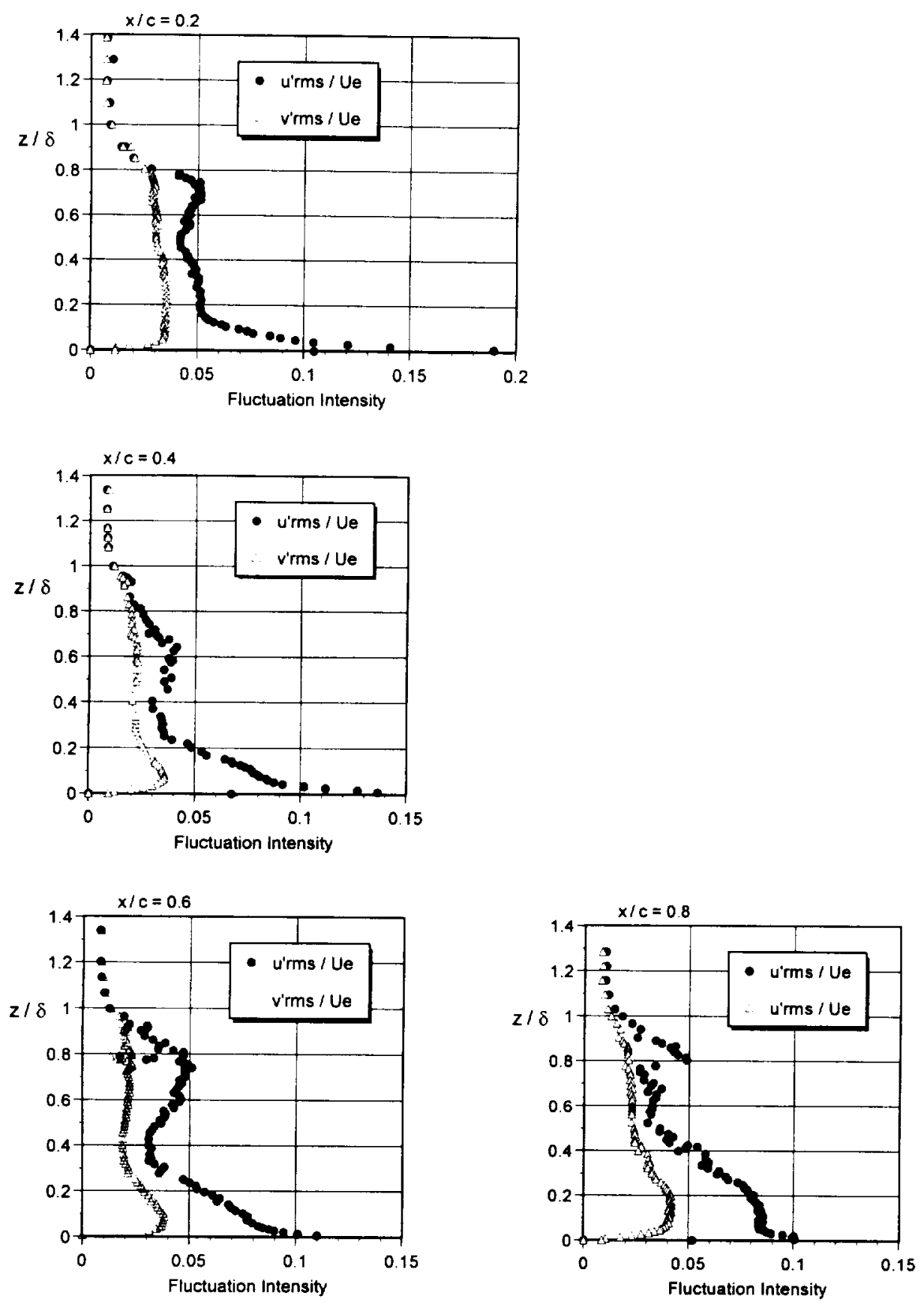

Figure 14. Tangential and Normal Component Turbulence Intensities for Case 1.

$\mathrm{x} / \mathrm{c}=0.2$ is different from the others in order to accommodate the higher near wall intensities. The $\mathrm{u}^{\prime}$ levels near the wall at the most upstream measurement location of $\mathrm{x} / \mathrm{c}$ $=0.06$ (profile not presented) is approximately $23 \%$ which is quite close to the intensity 
levels measured by hot-wire anemometry in the lower shear layer of the slat near wake. This suggests that the high turbulence levels near the wall originate from the interaction of the lower slat wake shear layer structure with the wall layer on the main element. With increased in $\mathrm{x} / \mathrm{c}$ the wall layer in case 1 appears to relax toward similar values of $\mathrm{u}^{\prime}$ and $\mathrm{v}^{\prime}$ intensity as occurred in case 2 . The case 1 turbulence intensity values in the outer part of the viscous layer are also greater than in case 2 but decay fairly rapidly with $\mathrm{x} / \mathrm{c}$. As was the situation in case 2 , there is a tendency for the turbulence associated with the wall region to spread toward the outer wake region.

Figure 15 presents non-dimensional $\overline{\mathrm{u}^{\prime} \mathrm{v}^{\prime}} / \mathrm{U}_{\mathrm{e}}^{2}$ profiles as measured at selected representative locations for case 2 . Outside the viscous layer $\overline{u^{\prime} v^{\prime}}$ approaches zero, consistent with the existence of an isotropic free stream turbulence. The variation of $\overline{u^{\prime} v^{\prime}}$ with $\mathrm{z} / \delta$ across the confluent boundary layer can be characterized by three regions. In the outermost region labeled " $\mathrm{A}$ " in Figure 15, the values are negative and nearly invariant with $\mathrm{x} / \mathrm{c}$. Recall the defect profiles of Figure 7 were approximately invariant with $\mathrm{x} / \mathrm{c}$ in this same region. Note that the case 2 mean velocity profiles show that $\partial \overline{\mathrm{U}} / \partial \mathrm{z}>0$ in region " $\mathrm{A}$ " so that the turbulence production term, $-\overline{\mathrm{u}^{\prime} \mathrm{v}^{\prime}} \partial \overline{\mathrm{U}} / \partial \mathrm{z}>0$. In region " $\mathrm{B}$ " $\overline{u^{\prime} v^{\prime}}$ is positive for $x / c<0.7$. However, for $x / c>0.7$ the sign reverses to negative in this region. Comparison with the corresponding mean velocity measurements indicates that $\overline{u^{\prime} v^{\prime}}>0$ is associated with portions of the mean profiles for which $\partial \bar{U} / \partial z<0$ so that again, turbulence production is positive. Of course $\partial \overline{\mathrm{U}} / \partial \mathrm{z}<0$ is indicative of the slat wake and, as pointed out in conjunction with Figure 7, the mean velocity profiles lose any region where $\partial \overline{\mathrm{U}} / \partial z<0$ for $\mathrm{x} / \mathrm{c}>0.7$. The case $2 \overline{\mathrm{u}^{\prime} \mathrm{v}^{\prime}}$ profiles of Figure 15 are shown 
to change sign accordingly. The case $2 \overline{u^{\prime} v}$ ' values nearest the wall are labeled " $C$ " in Figure 15 and are observed to be negative at all $\mathrm{x} / \mathrm{c}$ stations and grow in magnitude with $\mathrm{x} / \mathrm{c}$. The negative value is consistent with positive turbulence production since $\partial \overline{\mathrm{U}} / \partial \mathrm{z}>0$ closest to the wall. That the magnitude of the Reynolds stress grows with $\mathrm{x} / \mathrm{c}$ is consistent with the observation that the $u^{\prime}$ intensity in this region is nearly constant for case 2 . This being the case, since the mean shear diminishes with $\mathrm{x} / \mathrm{c}$ due to viscous wall layer growth, it follows that the Reynolds stress must grow in magnitude.

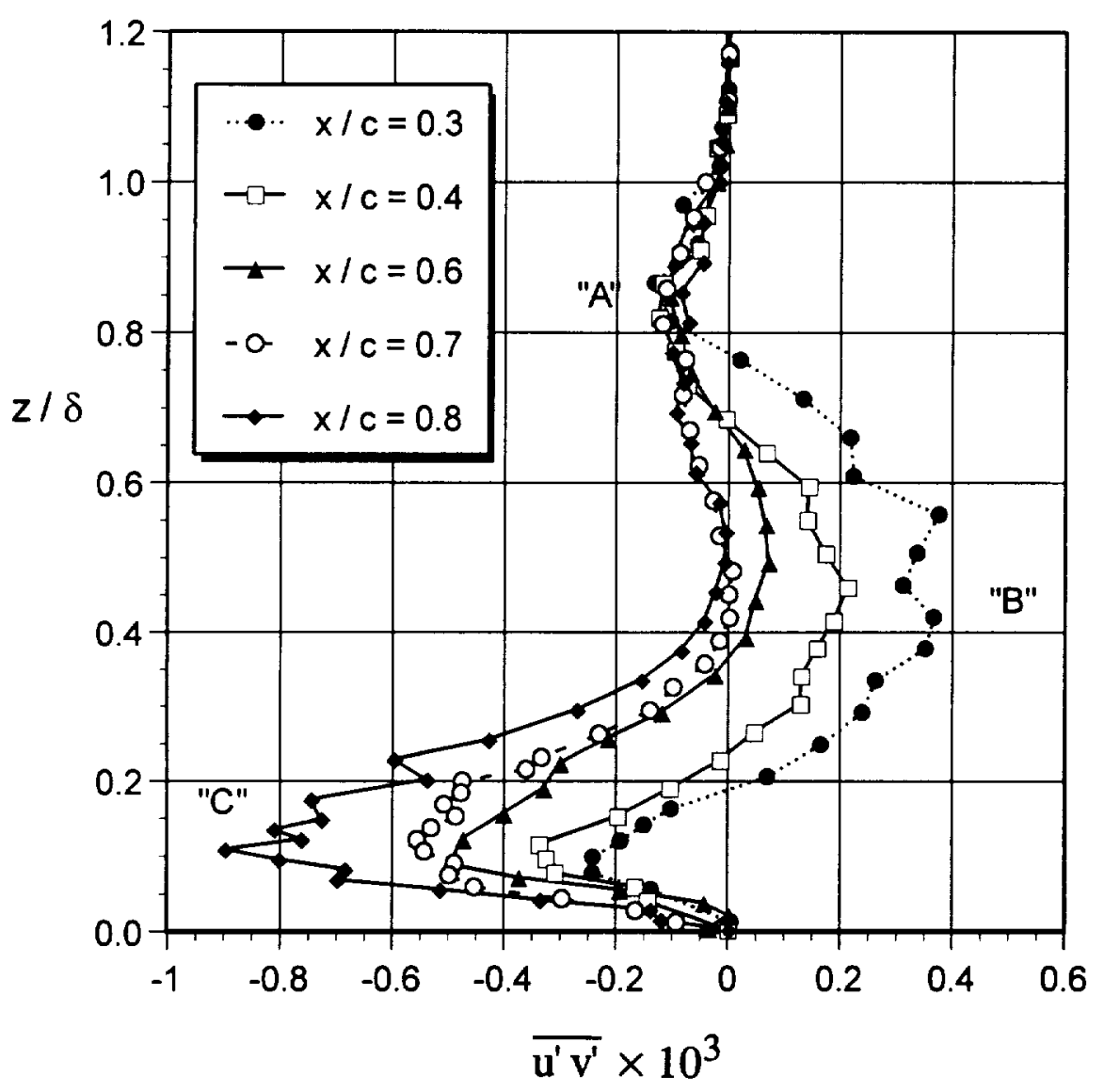

Figure 15. Non-Dimensional $\overline{u^{\prime} v^{\prime}}$ Profiles for Case 2. 
Although for most $\mathrm{z} / \delta$ the Reynolds stress and mean velocity gradient are correlated such that the turbulence production term is positive, this is not the case in a thin region near the boundary of regions " $\mathrm{B}$ " and " $\mathrm{C}$ " where counter gradient momentum transfer is observed to occur. As an example, Figure 16 compares the case $2 \overline{u^{\prime} v^{\prime}}$ and mean velocity profiles and shows two regions of $z / \delta$ where $\overline{u^{\prime} v^{\prime}}>0$ despite the fact that $\partial \overline{\mathrm{U}} / \partial z>0$. Such regions were found to exist for each $\mathrm{x} / \mathrm{c}<0.7$. This is important because it implies negative turbulence production so that standard eddy viscosity turbulence models will always fail in this region.
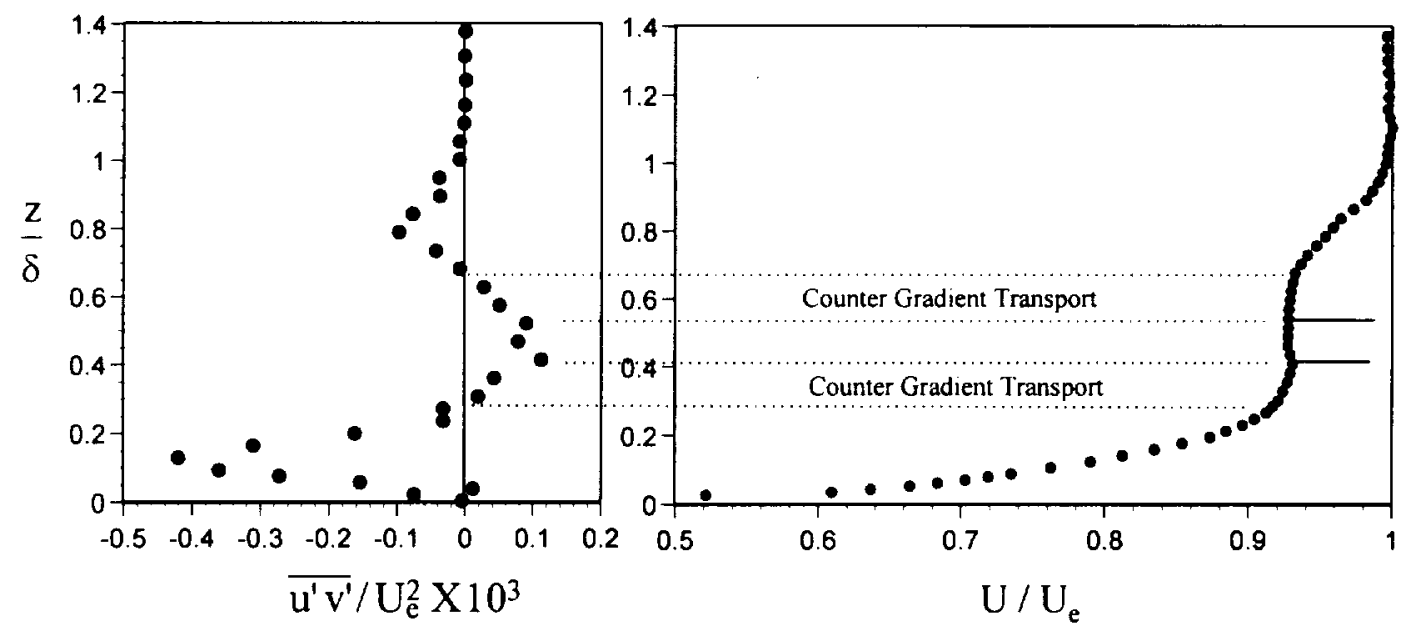

Figure 16. Regions of Counter-Gradient Momentum Transport.

Figure 17 presents $\overline{\mathrm{u}^{\prime} \mathrm{v}^{\prime}} / \mathrm{U}_{\mathrm{e}}^{2}$ profiles as measured at selected representative locations for case 1 . Note the increased scatter in the outer potion of the confluent boundary layer associated with the unsteady aspects of the wake. The region of positive Reynolds stress decays rapidly with $\mathrm{x} / \mathrm{c}$. However, as noted in the discussion surrounding the case 1 mean velocity profiles, there is no region of $\partial \bar{U} / \partial z<0$ for $x / c>0.4$. Hence, the small but 


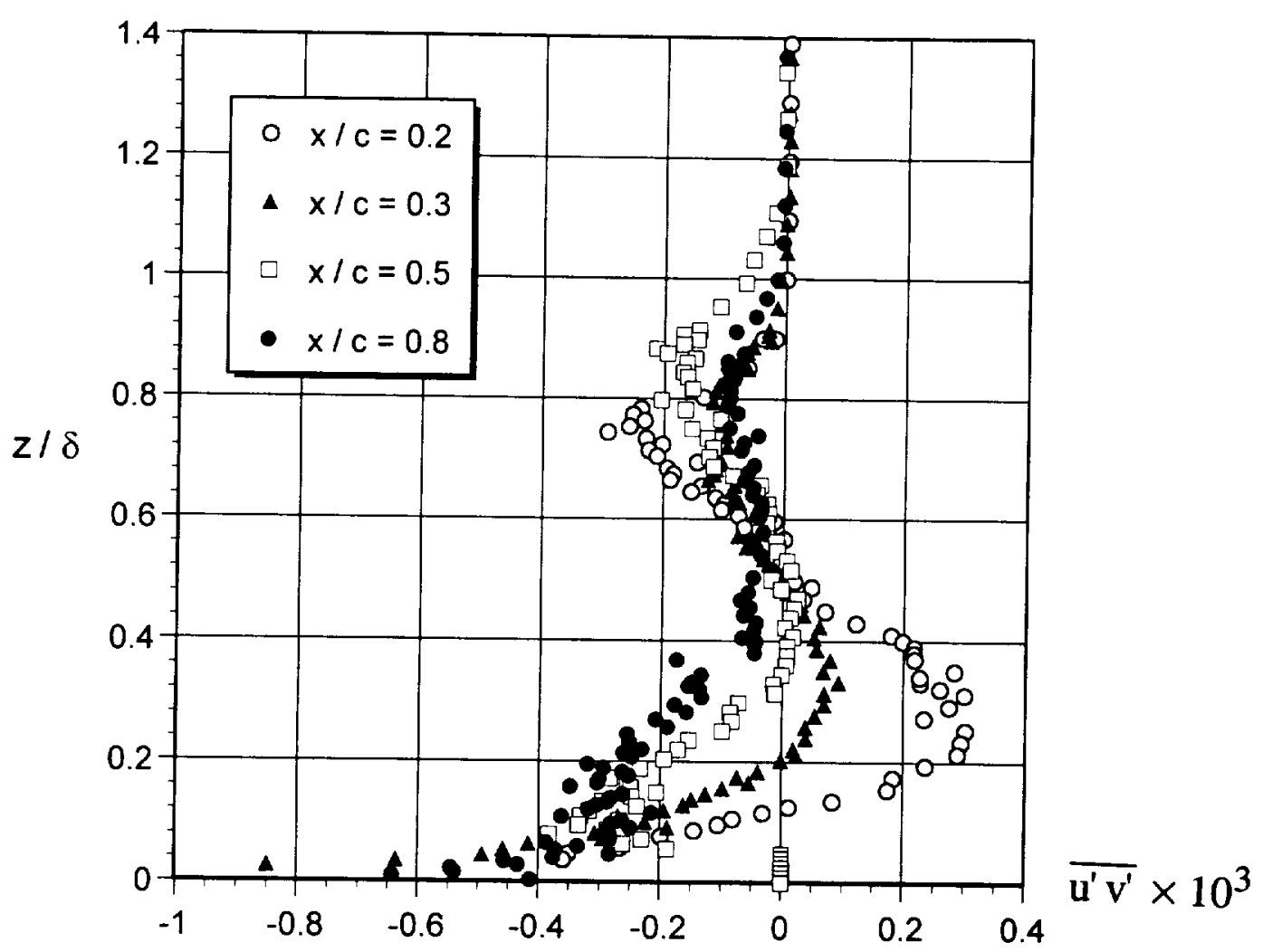

Figure 17. Non-Dimensional $\overline{u^{\prime} v^{\prime}}$ Profiles for Case 1.

positive $\overline{u^{\prime} v^{\prime}}$ values shown in Figure 17 for the $\mathrm{x} / \mathrm{c}=0.5$ would correspond to a region of counter gradient momentum transport.

\subsection{Unsteady Aspects of the High-Lift Flow Field}

One unanticipated result of the NASA NAG2-905 study is the observation of significant unsteady activity associated with the high-lift flow field. This unsteady activity appears capable of significantly influencing the global aerodynamics of the high-lift system.

The first indication of unsteady activity in the high-lift flow came from a comparison of the mean flow profiles for cases 1 and 2 as shown in Figure 5 of this report. Of interest 
is the increased scatter exhibited by the case 1 data set despite the fact that both cases were ensemble averaged over 10,000 coincident burst events. Further, as shown in Figure 5 , the scatter in the Case 1 mean flow data is clearly associated with the wake region. In contrast, Figure 5 shows very smooth profiles for the case 2 data. Comparison of the case 2 and 1 normal and lateral component turbulence intensities shown in Figures 13 and 14, respectively provide additional evidence of the unsteady character of the wake region for case 1 .

Motivated by the scatter in the case 1 mean flow and turbulence data, histograms of the case 1 LDV tangential and normal component velocity data were examined. These hisograms revealed a bimodal character as illustrated in Figure 18. In this figure the mean $U$ velocity profile at $x / c=0.1$ is shown for reference and the $V$-component velocity histograms are presented for various positions above the main element surface. Note that the histogram associated with the wake region has a distinct bimodal character suggesting the possibility of some type of "mode switching behavior". The histograms associated with the V-component were selected for presentation because their bimodal character is more apparent than for the U-component. The fact that this apparent mode switching behavior is occurring at $\mathrm{x} / \mathrm{c}=0.1$ suggests that it may originate in the vicinity of the slat.

In order to investigate the unsteady activity immediately downstream of the slat, constant temperature hot-wire anemometry was used. Figure 19 presents both mean flow and turbulence intensity profiles for case 1 as obtained $1 \mathrm{~mm}$ downstream of the slat trailing edge. A dashed line marks the trailing edge position. A standard "straight wire" probe with sensor diameter of $5 \mu \mathrm{m}$ was used for the measurement with the sensor aligned 


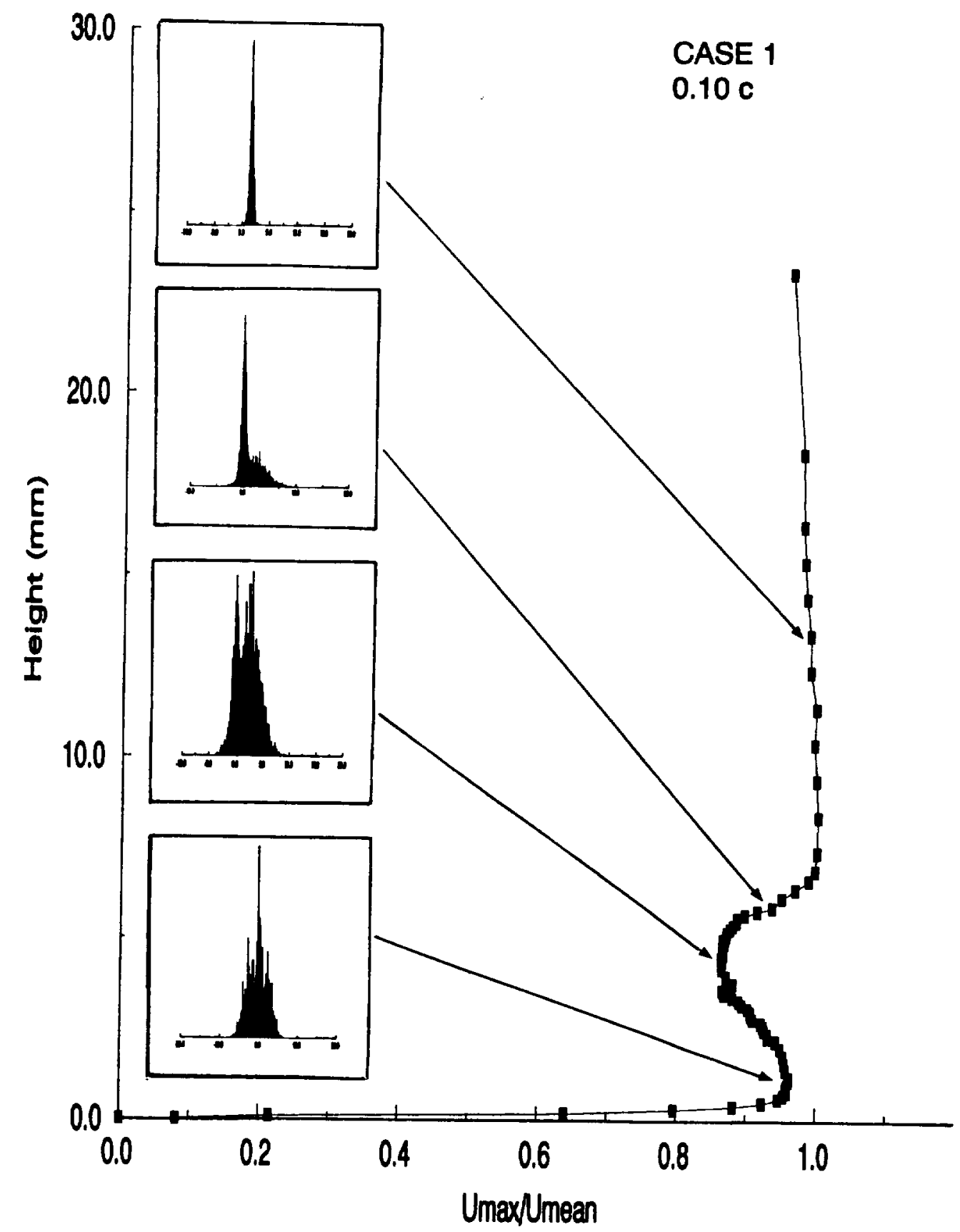

Figure 18. V-component velocity histograms for case 1 as obtained at $x / c=0.1$. in the spanwise direction. In this manner the cross-stream spatial resolution was very high. Note that Figure 19 shows that the highest fluctuation levels approach $23 \%$ and appear highly localized within the lower wake shear layer (and, hence, are associated with 

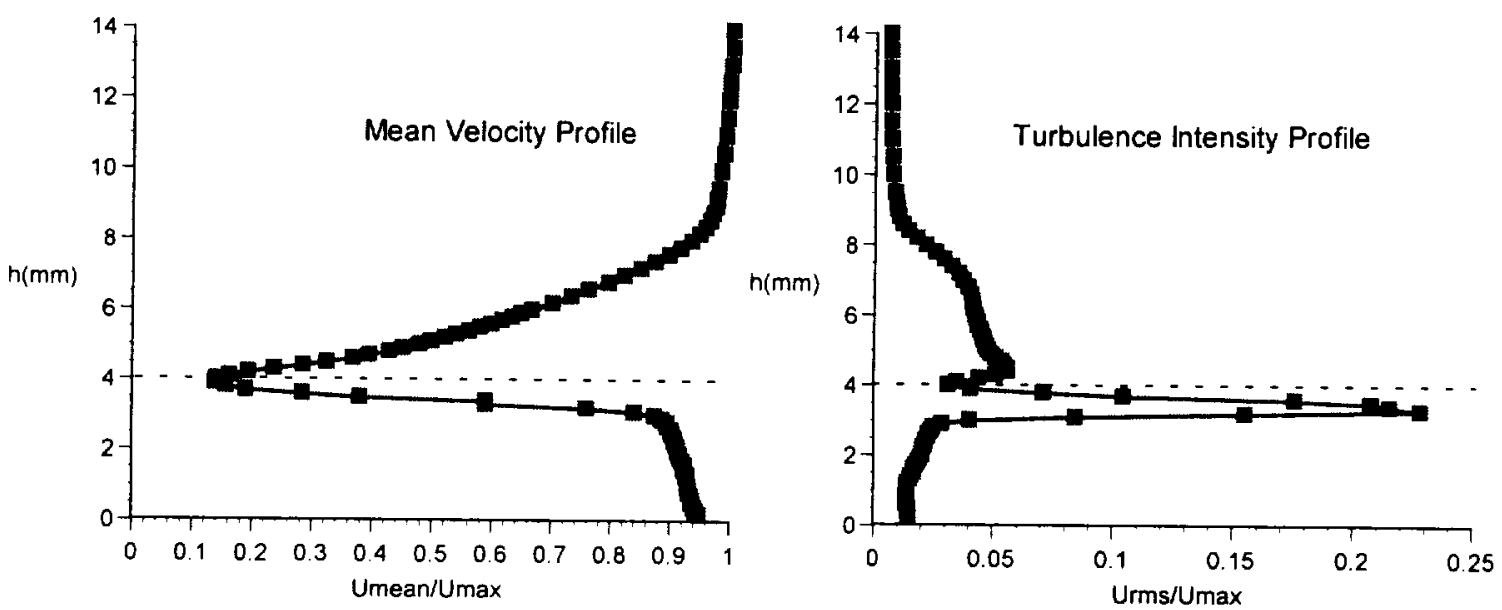

\section{Case $01,1 \mathrm{~mm}$ downstream of trailing-edge of slat, Hot Wire Measurement Results}

\section{Figure 19. Hot-Wire Measurements Obtained Immediately Downstream of the Slat.}

the lower slat surface). The fluctuation intensities in the shear layer from the top of the slat are much lower; peaking near $5 \%$.

Spectral analysis of the fluctuating velocity downstream of the slat was performed in order to characterize the frequency content of the observed wake velocity fluctuations. Standard Fast Fourier Transform methods were used in order to form the autospectral density of the fluctuating velocity. These results for case 1 are summarized in Figure 20 which presents velocity fluctuation spectra at five locations across the wake; the local mean wake velocity profile is presented as a reference. Note that the ordinate scales are arbitrary and are different in each case. These data clearly show two distinct shedding frequencies as evidenced by well defined spectral peaks. The two spectral peak frequencies are not harmonically related. Not surprisingly, the two dominant spectral 


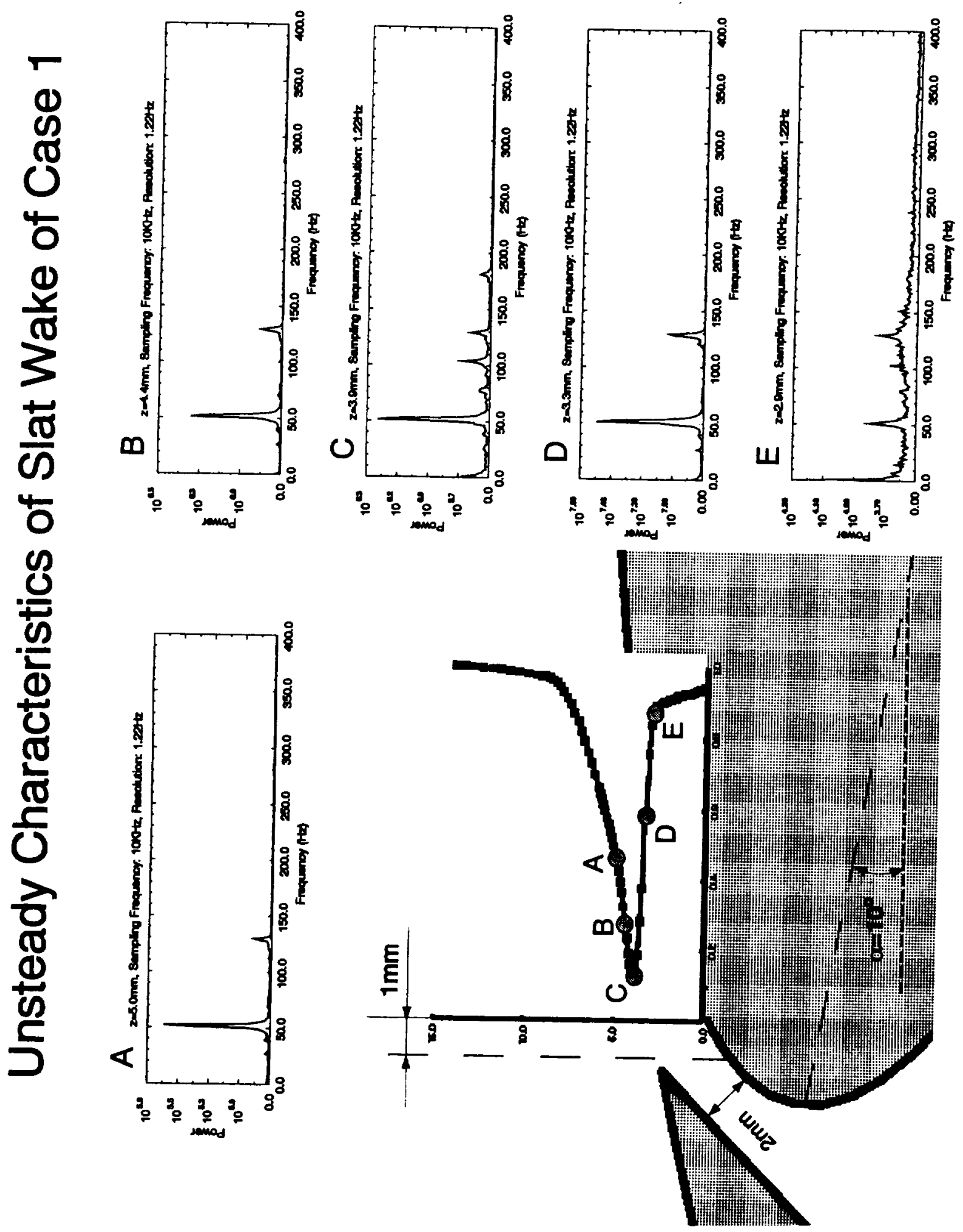

Figure 20. Autospectral Density Measurements of Wake Velocity Fluctuations 
modes reach peak amplitude near location " $D$ " corresponding to the slat lower surface.

Unfortunately, since the autospectral density measurement is an ensemble-averaged quantity, it is not possible to conclude whether the multiple spectral peaks in Figure 20 exist simultaneously or whether some type of mode switching behavior is involved. In order to obtain this type of time-scale localization, wavelet analysis of the hot-wire signals was also performed (see Lewalle ${ }^{12}$ ). A Morlet wavelet was used as the mother function. Figure 21 presents a map in time - scale space of the modulus of the wavelet transformed hot-wire signal for case 1. The wavelet transform results are plotted as shaded contours in the time-scale space. The abscissa is time in the usual sense of presenting time-series data. The ordinate is (event duration) $)^{-1}$ and is expressed in $\mathrm{Hz}$. Caution should be used here. We do not imply any periodicity; the use of $\mathrm{Hz}$ as an ordinate label is strictly a matter of convenience in relating the event scale to the spectral data presented in Figure 20. Note that the wavelet map shows that the shedding occurs at two distinct frequencies (which are indicated by arrows) but that it is quite intermittent. This figure also provides evidence of mode switching behavior. Although not presented here, similar data was obtained for the optimum case 2 . It was found that in case 2 the shedding from the slat cove occurs at essentially one scale and appears far more organized (i.e. less intermittent) than in case 1.

From these data it becomes clear that the observed unsteady flow behavior is a manifestation of unsteady activity in the slat cove. This likely takes the form of unsteady shedding and separated shear layer reattachment associated with the slat cove separation region. It should be noted that the unsteady behavior was observed for other cases as well. We have selected Case 1 for the illustrative purposes only. Although not documented in 


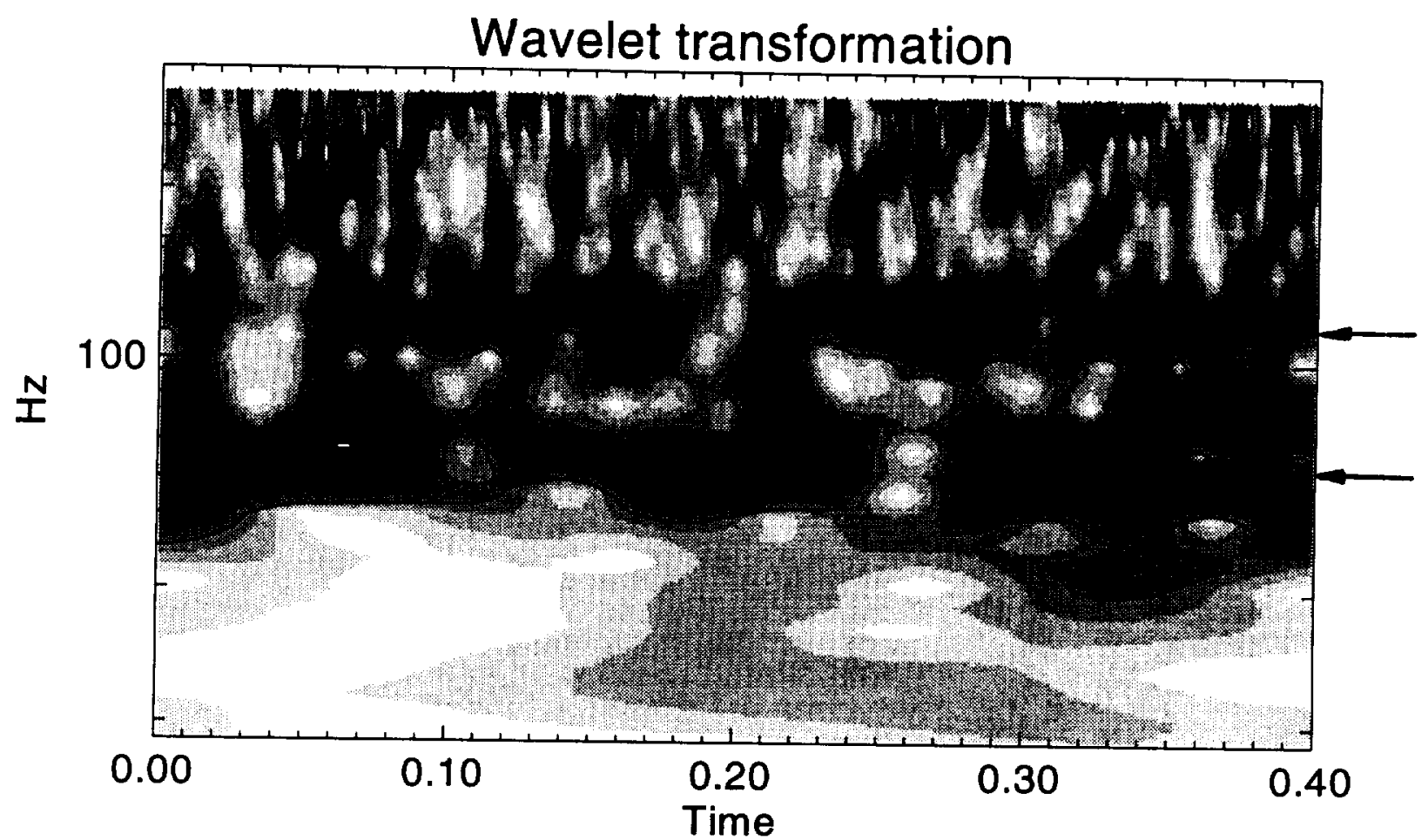

Figure 21. Wavelet Map of the Case 1 Slat Wake Velocity Fluctuations

detail in NASA NAG2-905, it should also be noted that cases which exhibited the unsteady flow behavior were also found to be associated with high levels of acoustic emission. This is consistent with recent work at NASA Ames which has shown that the leading edge slat region is a source of airframe noise.

In summary, the Notre Dame study has shown that for certain slat gap / overhang settings the slat wake is very unsteady. The unsteady activity appears to originate in the slat cove region. The unsteady slat wake interacts more aggressively with the main element boundary layer and influences the global aerodynamic characteristics of the high 
lift system. Also, as pointed out above, unsteady activity appears associated with significant acoustic emission from the slat cove region. To the best of the P.I.'s knowledge, the unsteady aspects of high-lift flows have not received a great deal of attention in the past. This is probably due to the fact that many experimental studies are geared toward Reynolds-averaged Navier-Stokes code validation. In such cases any disparities between computation and experiment are most often blamed on the turbulence model. Our results suggest that at least part of the observed disparity between computation and experiment may instead be due to the failure of RANS simulations to properly account for unsteady effects. Based upon our preliminary investigation, these unsteady effects appear capable of altering the high-lift flow field in a global sense and altering significantly the aerodynamic behavior. The slat cove region of commercial highlift systems has received little, if any attention, regarding aerodynamic treatment. It may be possible to employ passive flow control methodologies in the cove region in order to broaden the range of slat gap / overhang where optimum high-lift behavior may be achieved. Such passive flow control strategies also have the possibility of reducing slat noise.

\section{SUMMARY AND CONCLUSIONS}

It is well known that the aerodynamic performance of a multi-element airfoil is a function of the slat / main wing spacing and the trailing flap angle. What is not well known is why such small changes in the slat gap or overhang can cause significant changes in the net lift of the system. A goal of this study was to provide information on the flow physics associated with an optimum slat / main wing gap and overhang (maximum $\mathrm{C}_{\mathrm{lmax}}$ ) and several off optimum settings for a fixed trailing flap angle. This 
was accomplished through a combination of experiments correlating the system lift and detailed flow measurements. In this section we summarize several of the key findings of this work.

In this report we have contrasted cases of strong and weak slat wake / main element boundary layer confluence. Visualization of the slat wake and main element boundary layer provides global information on the character of the slat wake / main wing boundary layer interaction as well as regions of flow separation. The combined flow visualization and integrated pressure measurements show that optimum lift behavior is associated with slat positions for which confluence is delayed to aft chordwise locations. This was subsequently confirmed in detailed LDV surveys which show that for the non-optimum case the mixing between the slat wake and boundary layer starts very close to the wing leading-edge. For the optimum case mixing was delayed farther aft along the wing.

The integrated pressure measurement results also show the lift behavior to be very sensitive to slat position relative to the main element in terms of overhang and particularly gap setting. For too large a gap setting the beneficial effect of the slat downwash on moderating the main element pressure peak is lost, leading-edge separation results and lift is reduced. If the gap setting is too small the point of confluence between the slat wake and main element boundary layer moves forward. Such early confluence causes an increased momentum defect near the wall and an associated increase in displacement and momentum thickness over the main element. The streamline displacement has the effect of lowering the suction pressure on the main element and, consequently, lift is reduced. In a similar manner, lift is shown to be reduced for sufficiently large overhang settings. 
For illustrative purposes two cases were presented in detail in this report. Case 1 represents a forced early confluence between the slat wake and main element boundary layer by a small slat gap setting. Case 2 corresponds to a near optimum setting for which the confluence is delayed.

In both cases, despite obvious differences in the confluent boundary layer profiles from those of conventional turbulent boundary layers, it was found that sufficiently close to the wall inner variable scaling of the mean velocity results in the classic logarithmic law-of -the-wall variation. Velocity defect scaling is found to do a reasonable job of collapsing the profiles for $z / \delta>0.7$. For $z / \delta<0.7$, however, the defect grows with chordwise distance. The onset of confluence was defined to be the location where the slat wake and near wall profiles are separated by a nonzero defect, $U_{e}-\bar{U} \neq 0$. The criterion for strong confluence was taken to be the loss of any portion of the mean profile for which $\partial \overline{\mathrm{U}} / \partial \mathrm{z}<0$. For cases 1 and 2 this corresponded to $\mathrm{x} / \mathrm{c}=0.4$ and 0.7 , respectively.

An interesting feature of the non-optimum case was the unsteady behavior of the slat wake. In particular, the probability density functions of the case 1 fluctuating velocity (especially the $\mathrm{V}$ component) exhibited a bimodal character indicative of an inherently unsteady character to the flow. This was also evident as scatter in profiles of mean velocity and turbulence quantities in the outer wake portion of the confluent boundary layer. The origin of the unsteady behavior was traced to the slat cove and appears associated with the shedding of vorticity into the main element boundary layer. The optimum case did not exhibit this type of unsteady behavior.

For both cases 1 and 2 the $\mathrm{V}$-component mean velocity profiles showed behavior which was consistent with the superposition of downwash from the slat, streamline 
displacement away from the wall due to the viscous layer and the lateral entrainment flow induced by the presence of the slat wake.

For the optimum case 2, turbulence intensities peaked near the wall at values not unlike those of conventional boundary layers (around 10\%). Further, the intensity profile nearest the wall $\mathrm{z} / \delta<0.1$ was fairly constant with chordwise distance. The turbulence intensities in the outer portion of the confluent boundary layer associated with the slat wake decayed fairly rapidly with chordwise distance. For non-optimum case 1 , the turbulence intensities were much higher near the leading-edge, approaching $23 \%$ at the most forward measurement location. This was due to the lower shear layer of the slat wake feeding unsteady vorticity into the near wall region. These fluctuations decayed in the streamwise direction to reach values near $10 \%$ at the most aft chordwise locations. In both cases 1 and 2 there was an apparent transport of turbulence from the near wall region toward the outer wake portion of the confluent boundary layer.

Comparison of measured Reynolds stress and mean shear profiles indicate that for most locations within the confluent boundary layer their respective signs are such that the turbulence production term is positive. However in case 2 a region of counter gradient momentum transport was observed at each $\mathrm{x} / \mathrm{c}$ location for which the wake had not fully mixed with the wall layer and remained distinct. In case 1 counter gradient momentum transfer was observed even downstream of the onset of full mixing between the slat wake and wall layer.

From the results presented above, two obvious challenges that must be addressed in numerical simulations of confluent boundary layer flows involve dealing with counter gradient momentum transport and unsteady effects. The observation of counter gradient 
momentum transport is consistent with earlier work on confluent boundary layers performed by the Cambridge group ${ }^{5.8}$ some of which involved the interaction of an airfoil wake with the boundary layer on a wind tunnel wall. They commented that for wakes with strong coherent vorticity, counter gradient transfer was particularly notable. Hence it is not surprising given the demonstrated shedding of vorticity from the slat cove that counter gradient transport is apparent in this study. Of course counter gradient transport is equivalent to requiring a negative eddy viscosity. Hence any standard turbulence model, be it algebraic, $1 / 2,1$, or 2 equation, which has at its core the eddy viscosity concept will fail in such cases. Further, counter gradient momentum transport is observed primarily at forward chord locations where we can expect numerical marching schemes to be contaminated early on.

The importance of unsteady effects in influencing the global aerodynamics of highlift systems is suggested in this study. This aspect is currently under investigation. It is important to point out that to the authors' knowledge, the unsteady aspects of high-lift flows have not received a great deal of attention in the past. This is probably due to the fact that many experimental studies are geared toward Reynolds Averaged Navier-Stokes (RANS) code validation. Disparities between computation and experiment are usually blamed on the turbulence model. Our preliminary results suggest that some disparities may be due to the failure of RANS simulations to properly account for unsteady effects.

The experimental results presented in this paper represent a very small fraction of a large archival data base involving the interaction between a slat wake and main element boundary layer. In future work, the authors will perform numerical simulations of the experiments and investigate the effect of various turbulence models. Currently we are in 
the process of gridding up the experiment and working within the context of the CFL3D code. The authors will be happy to provide access to the full data set to those readers interested in performing their own CFD simulations. Those who are interested are invited to contact the authors.

\section{ACKNOWLEDGMENTS}

The authors wish to express their appreciation to Larry Erickson (retired) and Dale Satran of NASA Ames Research Center for their assistance and suggestions during the course of the study. The authors also wish to thank Dr. H. C. Chu who was involved with

both the flow visualization work and initial LDV measurements. This research effort was supported by NASA Ames Research Center, Moffett Field, CA., under grant NASANAG2-905. 


\section{REFERENCES}

'Smith, A.M.O., 1975, "High-Lift Aerodynamics," AIAA Journal of Aircraft, 12, 6, pp.
501-530.

${ }^{2}$ Mack, M.D., and McMasters, J. H., 1992, "High Reynolds Number Testing in Support of Transport Airplane Development," AIAA paper 92-3982.

${ }^{3}$ Chin, V.D., Peters, D.W., Spaid, F.W. and McGhee, R.J., 1993, "Flowfield Measurements About a Multi-Element Airfoil at High Reynolds Numbers," AIAA paper 93-3137.

${ }^{4}$ Bario, F., Charnay, G. and Papailiou, K. D., 1982, "An Experiment Concerning the Confluence of a Wake and a Boundary Layer," J. Fluids Engr., 104, pp. 18-24.

${ }^{5}$ Zhou, M. D. and Squire, L. C., 1983, "The Interaction of a Wake with a Boundary Layer," in Structure of Complex Turbulent Shear Flow, R. Dumas and L. Fulachier, Ed., Springer-Verlag, New York.

${ }^{6}$ Zhou, M. D. and Squire, L. C., 1985, "The Interaction of a Wake with a Turbulent Boundary Layer," Aeronautical Journal, pp. 72-81.

${ }^{7}$ Agoropoulos, D. and Squire, L.C., 1988, "Interactions Between Turbulent Wakes and Boundary Layers, "AIAA Journal, 26,10, pp. 1194-1200.

${ }^{8}$ Moghadam, A., and Squire, L.C., 1989, "The Mixing of Three-Dimensional Turbulent Wakes and Boundary Layers," Aeronautical Journal, pp. 153-161.

${ }^{9}$ Braden, J. A., Whipkey, R.R., Jones, G. S. and Lilley, D. E., 1983, "Experimental Study of the Separating Confluent Boundary Layer," NASA Contractor Report 3655, Volume1.

${ }^{10}$ Olson, L. E., 1978, "Optimization of Multielement Airfoils for Maximum Lift," Proceeding of the Advanced Technology Airfoil Research Conference, Langley Research Center, NASA Conference Publication 2045.

${ }^{11}$ Coles, D., 1956, "The Law of the Wake in the Turbulent Boundary Layer," J. Fluid Mech., 1, p. 191.

${ }^{12}$ Lewalle, J., 1994, "Wavelet Analysis of Experimental data:Some Methods and the Underlying Physics," AIAA paper 94-2281. 
